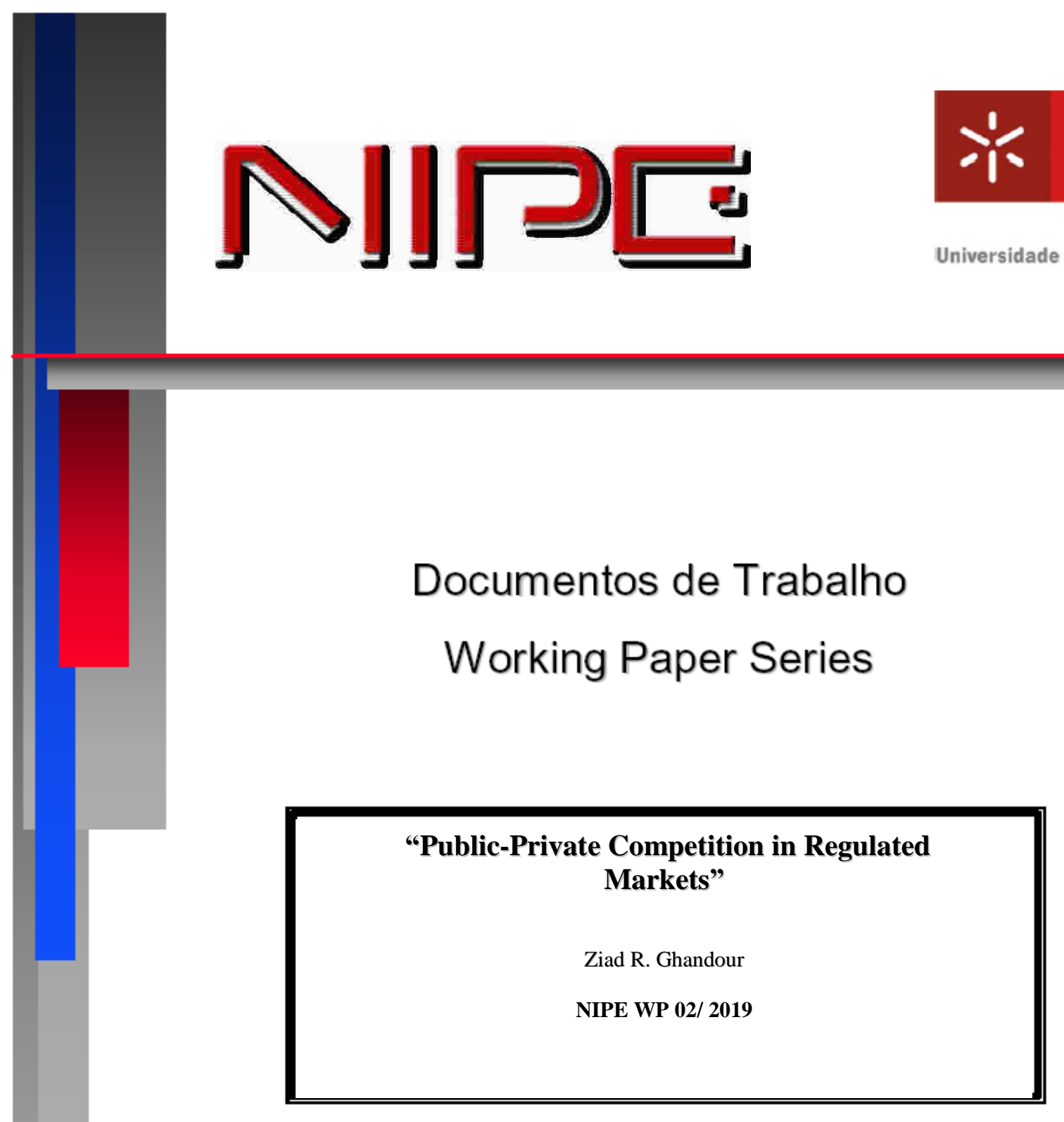

NÚCLEO DE INVESTIGAÇÃO EM POLÍTICAS ECONÓMICAS UNIVERSIDADE DO MINHO 


\section{"Public-Private Competition in Regulated Markets"}

Ziad R. Ghandour

NIPE* WP 02/2019

\section{URL:}

http://www.nipe.eeg.uminho.pt/

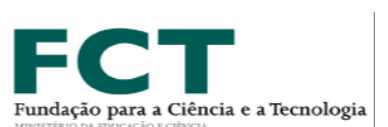

"This paper is financed by National Funds of the FCT - Portuguese Foundation for Science and Technology within the project «UID/ECO/03182/2019» 


\title{
Public-Private Competition in Regulated Markets *
}

\author{
Ziad R. Ghandour ${ }^{\dagger}$
}

March 26, 2019

\begin{abstract}
We analyse the effect of competition on quality provision in mixed markets, such as healthcare and education, where public and private providers coexist. We draw two key assumptions about the public provider in such markets, namely in that it faces a regulated price and is (partly) motivated. We also explore the effects of changes in the state subsidy and co-payment fees. Our main contribution is that, under certain circumstances, more competition leads to lower average quality in equilibrium. Similarly, the effects of higher co-payment fees or larger state subsidies on average quality are also a priori ambiguous. These conclusions hold regardless of whether providers seek profit maximisation or the public provider has altruistic preferences. Furthermore, we characterise the incentives for the private provider to unilaterally relocate towards the public provider.
\end{abstract}

Keywords: Mixed Duopoly, Competition, Quality Provision, Motivated Provider, State Subsidy, Co-payment Fees

JEL classification: D4, L1, L2, L3

*I would like to thank my supervisor: Professor Odd Rune Straume, who consistently allowed this paper to be my own work, but steered me in the right direction, whenever he thought I needed it.

${ }^{\dagger}$ Department of Economics / NIPE, University of Minho, Campus de Gualtar, 4710057 Braga, Portugal. E-mail: ziad.ghandour@gmail.com. 


\section{Introduction}

OECD 2017 report reads "Competition in public markets is often neglected or, in some cases, actively suppressed". The report seeks to design procompetitive reforms to derive quality improvements in the healthcare and education market sectors. Despite the goal of public provision to offer affordable access to merit goods, quality is a central concern for policymakers. Our paper is motivated by the observation that, whenever public and private providers coexist, quality differentiation varies. The public provider supplies higher quality than the private provider within the context of US nursing homes (Friedman et al., 2019) and the European education market (Romero and Del Rey, 2004), whereas, the scenario is reversed in most US universities (Deming and Goldin, 2012) and in the healthcare market in Lebanon and Bangladesh (Bemo, 2013; Pavel et al., 2015). One of the key policy challenges is how to ensure providers have more incentives so as to offer more quality provision in mixed markets.

Regulated markets have one important feature in common: government plays the central role of the major funder of the services to the public provide. ${ }^{1}$ In practice, governments tie the payment of subsidy to the provision of a particular service. Another important feature in several public sector areas is the use of co-payments. This was suggested by policymakers as a potential solution to control costs and to fund an increasingly costly education or healthcare system. ${ }^{2}$ Both policy instruments, state subsides and co-payment fees, act as competitive forces to produce desirable outcomes. Therefore,

\footnotetext{
${ }^{1}$ Historically, governments have contributed to public firms financial subsidies that result in an overall growth of the public sector. For instance, in 2015, education and healthcare markets account for circa 13 percent of the GDP and around 18 percent of public expenditure in OECD countries (OECD, 2017).

${ }^{2}$ For example, Sabik and Gandhi (2016) suggest that co-payments maybe an effective tool for reducing the use of the Emergency Department for non-urgent care.
} 
market mechanisms with these tools regulate the flow of services for the public provider which are mainly not available to private rivals, perhaps in selecting the range of quality standards.

Services in education, healthcare, long-term care, nursing homes and childcare markets have experienced a rapid growth in the private sector. ${ }^{3}$ According to Henry KFF, from 1999 to 2016, the US share of for-profit private hospitals has surged from 15.1 to 21.4 percent. ${ }^{4}$ Although most European markets in higher education and healthcare are dominated by public firms (where prices are typically regulated), the private market is very active. Jeurissen et al. (2016) report that for-profit hospital beds in eight European countries surged from about 15.6 percent in 2005 to 18.4 percent in 2013. In addition, the private sector facilities account for 74 percent of nursing home care in England (Barron and West, 2017). The private provider's incentive for quality investment depends on the total funds received by the public provider. In most countries, private providers compete on quality and price to attract consumers. For instance, in developed and emerging countries, elite private universities are allowed to set their own fees while public universities charge low tuition fees.

Under the applied co-payment system, consumers face trade-off in selecting the service provider who offers the highest quality as there is a share of costs paid directly by households. Based on purchasing behaviour, in some cases, the consumer would top-up the government contribution in order to purchase a higher quality service. More precisely, the responsiveness of the demand for higher quality is induced with larger marginal willingness-to-pay (WTP) for quality. In several countries, public healthcare providers charge

\footnotetext{
${ }^{3}$ The intention of this paper is not to blindly advocate for either deregulation or privatization.

${ }^{4}$ The Henry Kaiser Family Foundation (2017). State Health Facts, Hospitals by Ownership Type https : //www.kff.org/other/state-indicator/hospitals-by-ownership.
} 
lower fees than private facilities, but have less amenities and longer waiting times. In Lebanon, patients tend to prefer private clinics for their flexible measures, less crowded facilities and rapid procedures in providing medical services (Bemo, 2013). Therefore, the role of WTP for quality is useful for government and private sector in the allocation of their funds and in the setting of appropriate user fees (Pavel et al., 2015).

In this study, we focus on market outcomes in which the private provider competes in quality and price, while the public provider competes in the quality given at an exogenous level of state subsidy and co-payment fees. Within the framework of a horizontally differentiated mixed duopoly market, we study the nature of the strategic interaction between both providers under different ownership structures. We also examine the effect of competition and changes in policy instruments on average quality, thus highlighting the role of the consumers' marginal willingness-to-pay for quality. We address the following questions: If the goal is increasing quality provision, should the regulator increase state-subsidy per-consumer to the public provider or decrease the amount of co-payment? How does the private provider respond to changes in public policies? These questions are highly topical and of key importance. Thus, it is relevant, from a policy standpoint, to offer insight regarding the relation between key policy instruments and average quality in mixed markets, which has received relatively little attention in the existing literature.

We theoretically analyse the effect of competition on quality provision in mixed markets such as healthcare and education, where public and private providers coexist. We use a spatial competition framework as it is well-suited to study competition in such markets where consumers display a preference for the closest provider unless more distant providers offer better quality and/or lower price. We make two key assumptions about the public provider 
in such markets, namely that it faces a regulated price and is (partly) motivated. At stage one of the game, both providers simultaneously choose quality, while anticipating the price chosen by the private provider at the subsequent stage of the game. We consider the profit-maximising duopoly as a benchmark and explore the effects of heterogeneous objective functions. Surprisingly, our model fills the gap in the literature for mixed markets and has policy implications.

We develop two sets of results. The first, in the profit-maximising duopoly, concerns the public provider's best response which is strategically independent of the quality offered by the private provider. We find the relationship between competition and the quality of the private provider to be ambiguous. Furthermore, under certain circumstances, more competition leads to lower average quality in equilibrium. Similarly, the effects of higher co-payment fees or larger state subsidies on average quality are also a priori ambiguous. Lastly, if the private provider chooses its location, we find that it has an incentive to relocate towards the public provider, should the amount of state subsidy be sufficiently small.

Our second set of results takes a closer look at the additional chain of response when the public provider is altruistic. In this case, the best response function of the public provider has a strategic interaction with the quality of the private provider. We find the relationship between competition and quality of the public provider to be generally ambiguous. Additionally, the scope for positive relationship between average quality and competition is larger in the presence of altruism. Furthermore, we demonstrate that higher co-payment fees lead to lower quality for the public, should it be highly motivated. Our conclusion is that the relationship between average quality and state subsidy or co-payment fees can be defined as a priori ambiguous regardless of altruistic preferences. 
Within our model, we also investigate the effects of a higher share of copayment relative to the share of state-subsidy given that the public provider receives same price level. In a profit-maximising duopoly, we find that a higher share of co-payment has positive effect on equilibrium levels of the private provider, while it has no effect on the quality for the public. However, in the presence of altruism, the quality of the public provider has an inverse relation with the share of co-payment regardless of the level of altruism, in contrast to the result obtained under the effect of co-payment fees.

Our paper contributes to the theoretical literature on the relationship between competition and quality provision. Generally, more competition has two countering effects on quality. The direct effect, on the one hand, is that increased competition makes demand more responsive to a marginal increase in quality for given prices. ${ }^{5}$ On the other hand, the indirect effect, consumers are also responsive to price changes with more competition. The provider reduces the prices which, in return, reduces the marginal profit. Thus, lower prices reduces the provider's marginal return to quality investments. The ingredients of the theoretical model used determine the relative strength of these two general effects. ${ }^{6}$

Standard spatial competition models, where providers compete in prices and quality, reveal that the two aforementioned effects cancel each other out (produce neutrality results) exactly, hence; there is no effect of more competition on quality provision (Ma and Burgess, 1993; Gravelle, 1999). Two papers show that the two above-mentioned effects do not cancel when al-

\footnotetext{
${ }^{5}$ Wolinsky (1997); Matsumura and Matsushima (2007); Brekke et al. (2006) report a direct positive relation between competition and quality with regulated prices.

${ }^{6}$ For instance, under regulated prices, Brekke et al. (2011) find the effect of competition on quality in hospital markets to be ambiguous with a fairly general cost structure in the presence of altruism.
} 
lowing for income effects in consumer utility. Brekke et al. (2010) find that more competition tends to increase quality when consumers have decreasing marginal utility of income. Conversely, Brekke et al. (2017) find an unambiguously negative relationship between competition and quality if providers are (partly) motivated and utility is strictly concave in income. In this paper, where the private provider chooses quality and price, we investigate the characteristics that define the dominance of either effects in equilibrium.

In mixed markets, there is an impressive amount of studies examining the competition between state-owned maximising firm and profit-maximising private firm. In the literature on Hotelling-type spatial competition framework, our paper relates partly to Herr (2011) and Amin et al. (2018) where a forprofit hospital competes with a not-for-profit hospital on quality. However, both papers consider price regulation. In contrast, our model assumes that households either share part of the cost of the service (that is regulated co-payment) or an endogenous price chosen by the private provider. Accordingly, we fill the gap in the literature of competition in public markets. The private provider has a price choice compared to a price faced by the public provider, is considered to describe an additional feature in mixed markets yet to be explored.

With a vertical differentiation framework, where consumers are heterogeneous with respect to their willingness-to-pay for quality product, there is extensive literature studying quality and price competition (recent studies in the context of mixed duopoly (Stenbacka and Tombak, 2015; Laine and Ma, 2017; Klumpp and Su, 2018)). One recent study by Stenbacka and Tombak (2018) examines the effects of different market configuration (forprofit monopoly and mixed duopoly) on quality provision and optimal reimbursement policy. ${ }^{7}$ This analysis uses horizontal (rather than vertical)

\footnotetext{
${ }^{7}$ They state that the socially optimal reimbursement policy is invariant to the intro-
} 
differentiation for two reasons. First, we avoid heterogeneity in consumers' preferences to make our analysis more tractable. ${ }^{8}$ However, we highlight the importance of consumers' marginal willingness-to-pay for quality in our model. Second, there is strong empirical evidence that the traveling distance is one of the main predictors of consumer's choice of education or healthcare provider (De Fraja and Iossa, 2002; Kessler and McClellan, 2000; Tay, 2003).

Both quality differentiation and market equilibria may differ largely depending on the assumptions made and the country one looks at. For instance, Epple and Romano (1998) study the competition between public and private schools in the US and obtain that the quality for the former is lower compared to latter in equilibrium. ${ }^{9}$ On the contrary, Romero and Del Rey (2004), focused on a mixed duopoly market in European higher education market where public universities set higher admission standards and set almost zero tuition fees to maintain the quality of enrollments compared to commercially-run institutions with price policy only. ${ }^{10}$

Empirically, there is strong evidence that competition has a positive impact on the quality in education markets (Dee, 1998; Hoxby, 1994; Deming et al., 2012). When the price is a choice variable, the scenario is mixed. Some studies find a positive relation between competition and quality in the healthcare market (Cooper et al., 2011; Gaynor et al., 2013). However, a negative relationship between competition and quality is suggested by Grabowski (2004)

duction of for-profit competition with a premium quality directed towards high quality preference consumers.

${ }^{8}$ Hirth (1997) states "with heterogeneous quality preferences, there would be several sub-markets for different quality and cost combinations".

${ }^{9}$ They stated that if an equilibrium exits, then it is hierarchical in terms of innate ability and parent's income

${ }^{10}$ Cremer and Maldonado (2013) study mixed oligopoly equilibria with private and public schools. They examine how the equilibrium allocation (quality, tuition fees and welfare) is affected by the presence of public schools and by their relative position in the quality range. 
for nursing homes in the US. In England, Forder and Allan (2014) find that competition reduces the quality for care homes for the elderly. Propper et al. (2004); Burgess et al. (2008) find a positive relation between competition and mortality rates for patients with heart attack in England. ${ }^{11}$

The theoretical framework for the analysis of the behavioural effects of copayment takes its point of departure from the demand side. In hospital markets, empirical studies find either a very small or absence of any effect on use from changes in the co-payment in Belgium, France and Sweden respectively (Jakobsson and Svensson, 2016; Cockx and Brasseur, 2003; Chiappori et al., 1998). On the contrary, Landsem and Magnussen (2018) concluded that the introduction of a co-payment leads to an overall reduction of GP visits of 10-15 percent in Norway. In the education market, a recent empirical work on US public post-secondary institutions concludes that tuition cuts are less effective per-dollar than the spending increases on college attainment, in terms of degree completion and enrollment(Deming and Walters, 2017). Furthermore, Baum et al. (2014) show that college quality has declined in US due to a drastic decline in total-per student spending between 2000 and 2014 by 16 percent, even though the federal government has tripled expenditures on Federal financial aid over the last two decades. ${ }^{12}$

The rest of the paper is organised as follows. In Section 2, we outline the model, and in the subsequent section, we derive the equilibrium price and quality under the assumption of sequential choices. In Section 4, we analyse the effect of competition on quality provision and price; in addition, we study the effects of changes in the state subsidy, co-payment fees and share of co-

\footnotetext{
${ }^{11}$ For a comprehensive survey on competition and quality in healthcare markets, see (Gaynor and Town, 2011)

${ }^{12}$ Spending cuts may reduce degree completion by harming the quality of instruction, while limiting the number and variety of course portfolio, increasing class size, or moving students into non-credit-bearing remedial courses (Bettinger and Long, 2009; Bahr, 2014)
} 
payment on equilibrium outcomes. In Section 5, we consider two extensions: direct provision information (public reporting) and relocation incentives for the private provider. The paper is concluded in Section 6 .

\section{$2 \quad$ Model}

We employ the standard Hotelling (1929) duopoly model in regulated markets where consumers are uniformly distributed on the line segment $L=[0,1]$. There are two providers indexed by $j=1,2$ and each chooses a quality level $q_{j}$. Provider 1 (provider 2) is the public (private) provider and located at the left (right) endpoint of the line. As in D'Aspremont et al. (1979), we use quadratic consumer transportation cost to avoid discontinuities in the providers' profit functions. Each consumer demands one unit of the product. The utility of a consumer who is located at $z \in L$ and getting a unit of the product from provider $\mathrm{j}$ is given by: 13

$$
U_{j}(z)=\left\{\begin{array}{lll}
\bar{U}+\beta q_{1}-T-t z^{2}, & \text { if } & \text { public } \\
\bar{U}+\beta q_{2}-p_{2}-t(1-z)^{2}, & \text { if } & \text { private }
\end{array}\right.
$$

We assume $\bar{U}$ is so large that each customer consumes one unit of the product. Consumers are identified by a parameter $\beta>0$ that characterizes their preferences over qualities. Given the utility function, $\frac{\partial U_{j}(z)}{\partial q_{j} \partial \beta}>0$, a higher $\beta$ reflects a higher marginal willingness to pay for quality (consumers always prefer higher quality). The parameter $t>0$ reflects the degree of horizontal product differentiation like the heterogeneity of services. An alternative physical interpretation of $t$ is a traveling cost parameter which includes all

\footnotetext{
${ }^{13}$ If each provider chooses a location $x_{j} \in L$ where we assume $\Delta=x_{2}-x_{1}$ and $x_{2} \geq x_{1}$ , then $[\mathrm{t} \Delta]$ appears as a multiplicative term in all equilibrium functions. Accordingly, we used fixed locations to avoid redundancy $(\Delta=1)$ as both parameters t and $\Delta$ have exactly the same effect.
} 
monetary costs incurred while traveling to the location of the provider $\mathrm{j}$. The regulator sets the co-payment, $T$, and the public provider follows the level of regulatory commitment. In the absence of price as a strategic variable for the public provider, the private provider has both quality and price choices. Accordingly, $p_{2}$ is endogenous in our model compared to exogenous product price for the public provider. Marginal utility of income is constant and same for all consumers. Hence, the income distribution has no impact on our results. Given that $\bar{U}$ in Equation (1) is assumed to be equal for all consumers, the location $z$ of the consumer who is indifferent between buying the service from either provider is solved by: $\beta q_{1}-T-t z^{2}=\beta q_{2}-p_{2}-t(1-z)^{2}$. With a uniform distribution of consumers, demand faced by the public provider and the private provider is $D_{1}=z$ and $D_{2}=1-z$, respectively. Hence, the market share for the public provider is given by

$$
D_{1}=\frac{t+p_{2}-T-\beta\left(q_{2}-q_{1}\right)}{2 t}
$$

Accordingly, the private provider gets the remainder of the consumers: $D_{2}=$ $1-D_{1}$

We assume that output (denoted $D_{j}$ ) and quality (denoted $q_{j}$ ) are separable in costs. Apart from considering fixed costs, the cost function is given by: ${ }^{14}$

$$
C\left(D_{j}, q_{j}\right)=c D_{j}+\frac{k}{2} q_{j}^{2}
$$

The costs are linear in the output and convex in quality $C_{q}>0, C_{q q}>0$ and $C_{q=0} \equiv c D_{j}$. Accordingly, we assume the marginal cost of production (denoted c) is constant. In addition, $k>0$ is a cost parameter related to quality investment. The government transfers state subsidy to the public provider per each unit demand of the consumer for the service, denoted $\lambda$. We assume both parameters $T$ and $\lambda$ are exogenous (regulated) in our

\footnotetext{
${ }^{14}$ This model setting is a widely used assumption in the literature (Economides, 1989; Barros and Martinez-Giralt, 2002; Calem and Rizzo, 1995; Brekke et al., 2006)
} 
model. Furthermore, we make the following parameter assumptions: $T \leq c$ and $T+\lambda>c$. The former explains that consumers pay at most the fees equal to the marginal cost of production. The latter asserts that the total price received by the public provider $\left(p_{1}=\lambda+T\right)$ is strictly higher than the marginal cost.

In order to ensure non-negative profits for the public provider, we assume it receives a lump sum-transfer (philanthropic source of finance or a block grant that does not affect the provider's actions) from the government, denoted B. The profits of the provider $\mathrm{j}$ is given by

$$
\pi_{j}= \begin{cases}B+\left(p_{1}-c\right) D_{1}-\frac{k}{2} q_{1}^{2}, & \text { if public } \\ \left(p_{2}-c\right) D_{2}-\frac{k}{2} q_{2}^{2}, & \text { if private }\end{cases}
$$

The objective function of the public provider reflects an additional element, namely, altruistic preferences. As there will be no perfect alignment with the social planner, the degree of motivation for the public is assumed to enter directly in the objective function. ${ }^{15}$ Hence, the public provider maximizes profits in addition to certain level of altruism, denoted by $\alpha$, towards the quality offered to consumers. ${ }^{16}$ Consequently, the payoff of the public provider is given by

$$
W=\pi_{1}+\alpha \int_{0}^{D_{1}}\left(\bar{U}+\beta q_{1}\right) d y
$$

In our framework, the private provider potentially differs from the public provider along two different dimensions: profit orientation (for-profits have

\footnotetext{
${ }^{15}$ In public sector, literature on motivated agents shows that they have no perfect alignment with the objective function of the principals (Francois and Vlassopoulos, 2008; Makris, 2009; Prendergast, 2007)

${ }^{16}$ Tonin and Vlassopoulos (2010) disclose an experimental evidence of altruistic preferences.
} 
profit margin goals) and $p_{2}$ as a choice variable. To better facilitate a comparison with the benchmark model, we consider both providers share the same objective function, namely profit maximization. Later, we assess how the degree of motivation for the public provider impacts the equilibrium outcomes.

We use a spatial competition framework to study the effect of more competition (reduction in a traveling cost parameter, $t$ ) on quality provision in a two-stage game. In addition, we study the relationship between average quality and changes in the state subsidy and co-payment fees. For the main part of the analysis, we allow for sequential choices where quality is treated more as a long term variable. ${ }^{17}$ We consider the following two-stage game:

- Stage 1: Both providers simultaneously choose $q_{1}$ and $q_{2}$

- Stage 2: The private provider chooses the price level $p_{2}$.

This sequence of moves is widely used in the literature. The existing theoretical models consider price choice in the second stage where both providers obtain the price set for a given pair of quality levels $\left(q_{1}, q_{2}\right)$ respectively. This kind of Bertrand competition differs from our model because only the public provider is facing a fixed product price. To our knowledge, the present paper is the first attempt to analyze competition in such settings. Later, we extend our model in two dimensions: First, we check if the private provider has an incentive to relocate unilaterally towards the public provider. Second, we examine the impact of more public reporting on the quality provision in equilibrium.

\footnotetext{
${ }^{17}$ Our results hold regardless of whether quality and price decisions are made simultaneously or sequentially
} 


\section{Nash Equilibrium}

We start out by deriving the Nash Equilibrium for a given $p_{1}$ (regulated) in order to analyze how the providers' choices of quality and price are determined under symmetric locations. As usual, the game is solved by backward induction.

\subsection{Optimal Private Price}

First, we discuss the optimal price for the private provider in the second stage of the game. For a given pair of quality levels, the optimal price is computed by taking the first-order condition in Equation (4) which yields: 18

$$
p_{2}=\frac{T+c+t+\beta\left(q_{2}-q_{1}\right)}{2}
$$

Co-payment fees $(T)$, marginal cost of production $(c)$ and the transportation costs $(t)$ have direct (positive) effects on the optimal price for the private provider. If we consider $t$ as product space interpretation of horizontal differentiation, all else equal, the private provider responds to increase $p_{2}$ if the market faces higher level of heterogeneity in the services offered. Moreover, the optimal price depends on the quality difference $\left(q_{2}-q_{1}\right)$. All else equal, the higher $q_{2}$ is relative to $q_{1}$, the higher is the price, $p_{2}$. We see that the optimal price and rival's quality are strategic substitutes $\left(\frac{\partial p_{2}}{\partial q_{1}}<0\right)$.

\subsection{Quality Competition}

We consider the equilibrium in the first stage of the game. Both providers choose simultaneously the quality levels in anticipation of the optimal price for the private provider. Substituting Equation (6) into Equation (4) and

\footnotetext{
${ }^{18}$ Second order condition satisfies the global maximum criterion $\frac{\partial^{2} \pi_{2}}{\partial p_{2}^{2}}<0$.
} 
maximizing Equations (4-5) with respect to quality levels $\left(\frac{\partial W}{\partial q_{1}}=0, \frac{\partial \pi_{2}}{\partial q_{2}}=0\right)$ yields the first -order conditions for provider 1 and 2 which implicitly define best response functions $q_{1}\left(q_{2}\right)$ and $q_{2}\left(q_{1}\right)$ respectively. The second order conditions $\left(\frac{\partial^{2} W}{\partial q_{1}^{2}}<0\right.$ and $\left.\frac{\partial^{2} \pi_{2}}{\partial q_{2}^{2}}<0\right)$ are always satisfied for: $2 k t>\alpha \beta^{2}$ and $4 k t>\beta^{2}$. Moreover, uniqueness and stability of the equilibrium is confirmed by the positive sign of the Jacobian if: ${ }^{19} \alpha<\frac{4 k t\left(4 k t-\beta^{2}\right)}{\beta^{2}\left(8 k t-\beta^{2}\right)}$.

The best response functions $q_{1}\left(q_{2}\right)$ and $q_{2}\left(q_{1}\right)$ are given by

$$
\begin{gathered}
q_{1}\left(q_{2}\right)=\beta \frac{(T+\lambda-c)+\alpha\left(3 t+c+\bar{U}-T-\beta q_{2}\right)}{2\left(2 k t-\alpha \beta^{2}\right)} \\
q_{2}\left(q_{1}\right)=\beta \frac{\left(T-c+t-\beta q_{1}\right)}{4 k t-\beta^{2}}
\end{gathered}
$$

Quality is optimal when the marginal benefit from increased demand equals the marginal cost of quality provision. The nature of strategic interaction in $q_{1}\left(q_{2}\right)$ behaves differently as it depends on the degree of altruism $\left(\frac{\partial q_{1}}{\partial q_{2}}<(=) 0\right.$ if $\alpha>(=) 0)$. First, if $\alpha=0$, neither marginal revenue nor marginal cost for the public provider depends on $q_{2}$, the quality of the private provider. ${ }^{20}$ Hence, $q_{1}$ is strategically independent of $q_{2}$ when both providers are pure profit-maximisers. Second, if $\alpha>0$, the public provider has marginal nonfinancial benefit from aggregate consumer utility as an additional term. The marginal payoff of quality is increasing in $\alpha$. A marginal revenue of quality increase is captured by two effects in the following term

$$
\begin{aligned}
& 19 \frac{\partial^{2} W}{\partial q_{1}^{2}} \frac{\partial^{2} \pi_{2}}{\partial q_{2}^{2}}-\frac{\partial^{2} W}{\partial q_{1} \partial q_{2}} \frac{\partial^{2} \pi_{2}}{\partial q_{1} \partial q_{2}}=\frac{\left(\beta^{2}-4 k t\right)\left(\alpha \beta^{2}-2 k t\right)}{8 t^{2}}-\frac{\alpha \beta^{4}}{16 t^{2}}>0 . \\
& { }^{20} \mathrm{MR}=(T+\lambda-c) \frac{\partial D_{1}}{\partial q_{1}}=\frac{(T+\lambda-c) \beta}{2 t} \text { and } \mathrm{MC}=k q_{1}
\end{aligned}
$$




$$
\alpha\left(\beta D_{1}+\left(U+\beta q_{1}\right) \frac{\partial D_{1}}{\partial q_{1}}\right)
$$

The first term shows the existing consumers get higher utility and it is known as the "inframarginal" utility increase. The second term is the marginal utility increase which captures the utility of new consumers. Nevertheless, the inframarginal utility increase is affected by $q_{2}$. The demand of the public provider $\left(D_{1}\right)$ is decreasing in $q_{2}$. A higher $q_{2}$ leads to lower $D_{1}$ which means fewer consumers benefit from an increase in $q_{1}$. When the public provider is altruistic $(\alpha>0)$, this reduces the marginal benefit of quality investments. Accordingly, all else equal, higher $q_{2}$ leads to lower $q_{1}$.

The best response function $q_{2}\left(q_{1}\right)$ has an inverse relation with rival's quality $\frac{\partial q_{2}\left(q_{1}\right)}{\partial q_{1}}=-\frac{\beta^{2}}{4 k t-\beta^{2}}<0$. This strategic interaction holds true at any degree of altruism. Higher $q_{1}$ leads to lower $D_{2}$, which, in return, makes the demand more price elastic. A lower $p_{2}$ leads to lower $q_{2}$ (price and quality are complementary strategies). Notice that regardless the level of $\alpha, q_{1}\left(q_{2}\right)$ is monotonically increasing in the state subsidy while this parameter $(\lambda)$ does not appear in $q_{2}\left(q_{1}\right)$.

If the Subgame Perfect Nash Equilibrium is an interior solution, the equilibrium outcome is given by

$$
\begin{gathered}
q_{1}^{*}=\beta \frac{(T+\lambda-c)\left(4 k t-\beta^{2}\right)+\alpha \theta}{4 k t\left(4 k t-\beta^{2}\right)-\alpha \beta^{2}\left(8 k t-\beta^{2}\right)} \\
q_{2}^{*}=\beta \frac{(T-c)\left(4 k t-\beta^{2}\right)+4 k t^{2}-\beta^{2} \lambda-\alpha \phi}{4 k t\left(4 k t-\beta^{2}\right)-\alpha \beta^{2}\left(8 k t-\beta^{2}\right)} \\
p_{2}^{*}=\frac{2 k t\left[\left(4 k t-\beta^{2}\right)(T+c)+4 k t^{2}-\lambda \beta^{2}\right]-\alpha \mu}{4 k t\left(4 k t-\beta^{2}\right)-\alpha \beta^{2}\left(8 k t-\beta^{2}\right)}
\end{gathered}
$$


where $\theta=\bar{U}\left(4 k t-\beta^{2}\right)+4 t\left(3 k t-\beta^{2}+k(c-T)\right), \phi=\beta^{2}(T+5 t+\bar{U}-c)$, $\mu=\beta^{2}\left[2 k t(T+\bar{U}+5 t)+c\left(6 k t-\beta^{2}\right)\right]$.

Equilibrium Existence for Quality In order to ensure the existence of equilibrium with interior solutions, we need the quality levels for both providers to be be always positive. In the appendix, we present the conditions for the public provider $\left(\lambda>\underline{\lambda}\right.$ so that $\left.q_{1}>0\right)$ and the private provider $\left(\lambda<\bar{\lambda}\right.$ so that $\left.q_{2}>0\right)$ respectively. We can summarize the results which require additional conditions to be satisfied so that $\underline{\lambda}<\lambda<\bar{\lambda}$, where

$$
\underline{\lambda}:=c-T
$$

and

$$
\bar{\lambda}:=\frac{(T-c)\left(4 k t-\beta^{2}\right)+4 k t^{2}-\alpha \beta^{2}(5 t+T+\bar{U}-c)}{\beta^{2}}
$$

For $\alpha=0, \bar{\lambda}>\underline{\lambda}$ if $t>c-T$. When $\alpha \neq 0$, we require the previous condition in addition to necessary level of altruism: $\alpha<\frac{4 k t\left(4 k t-\beta^{2}\right)}{\beta^{2}\left(8 k t-\beta^{2}\right)}$. Hence, the degree of altruism has the following lower and upper bound: $\underline{\alpha} \leq \alpha<\bar{\alpha}$ where $\underline{\alpha}=0$ and $\bar{\alpha}=\frac{4 k t\left(4 k t-\beta^{2}\right)}{\beta^{2}\left(8 k t-\beta^{2}\right)}$ respectively.

\subsubsection{Nature of Vertical Differentiation}

We characterize the features in the product's respective level of quality for both providers. What are the incentives for the private provider to supply higher quality than the public provider? Given the equilibrium outcomes, the quality differentiation $\left(q_{2}-q_{1}\right)$ is given by

$$
q_{2}^{*}-q_{1}^{*}=\beta \frac{4 k t[t-\lambda]-\alpha\left[12 k t^{2}(c-T)\left(4 k t-\beta^{2}\right)+t\left(4 k \bar{U}+\beta^{2}\right)\right]}{4 k t\left(4 k t-\beta^{2}\right)-\alpha \beta^{2}\left(8 k t-\beta^{2}\right)}
$$


Proposition 1: (i) If the public provider is a profit-maximiser, the private provider offers higher (lower) quality in equilibrium than the public if the degree of product differentiation is sufficiently large (small) relative to the state subsidy. (ii) The presence of altruism reduces the scope for the private provider to have higher quality provision than the public provider in equilibrium.

Proof: (i) If $\alpha=0$, the numerator in (12) reduces to $\beta(t-\lambda)$ which is positive if $t>\lambda$. Thus, if $\alpha=0, q_{2}^{*}>q_{1}^{*}$ if $t>\lambda$. (ii) In the presence of altruism, the statement is true if the second square bracket is positive, which follows immediately from (12). To put differently, there exists a threshold $\hat{t}$ where $\hat{t}>\lambda$ such that $q_{2}^{*}>q_{1}^{*}$ if $t>\hat{t}$. Conversely, $q_{2}^{*}<q_{1}^{*}$ if $t<\hat{t}$.

The first part of Proposition 1 shows that if both providers are profit oriented, the public provider is the high-quality provider if $t<\lambda$. A large $\lambda$ increases the marginal revenue of quality for the public provider (higher

$\left.q_{1}\right)$. Due to strategic substitutability $\left(\frac{\partial q_{2}}{\partial q_{1}}<0\right)$, it leads to lower $q_{2}$. Therefore, the incentive for the private to supply higher quality than the public provider is reinforced if the amount of state subsidy received by the regulator is sufficiently small. In the presence of altruism, the intuition is straightforward. A high level of motivation towards the quality $(\alpha>0)$ increases the marginal revenue of quality (higher $q_{1}$ ), which, in return, lowers $q_{2}$ due to strategic substitution. Therefore, if $\alpha>0$, the quality of the public provider dominates for a larger set of parameters.

\section{Effects of Competition and Regulatory Tools}

The impact of more competition (measured by a reduction in transportation costs) on quality is clear when prices are regulated. Competition leads to more quality when price is above marginal cost. In our framework, the public 
provider only chooses the quality for a given regulated price. On the contrary, the private provider chooses both quality and price. Hence, more competition makes demand more responsive to changes in qualities and prices. This generates two effects on the incentives for quality provision: one direct and one indirect. For a given price, the provider has an incentive to increase its quality provision in order to attract more consumers, who are now more responsive to such a quality increase. This is the direct effect. On the other hand, since more competition also makes consumers more response to price changes, the private provider has an incentive to reduce the price. However, a price reduction reduces the private provider's profit margin, and therefore reduces the provider's incentive to attract more demand by increasing quality. In other words, a lower price reduces the provider's return to quality investments. This indirect effect counteracts the aforementioned direct effect and makes the relationship between competition and quality provision a priori ambiguous for the private provider. In our framework, if the public provider is committed to follow a regulated price, $p_{1}$, does more competition induce providers to offer higher-quality services?

\subsection{Price and Quality Effects of Competition}

Using transportation costs as an inverse measure of the degree of competition, we analyze the effect of more competition (lower $t$ ) on equilibrium quality level of the public provider, by differentiating the followings:

$$
\frac{\partial q_{1}^{*}}{\partial t}=-4 \beta \frac{k(T+\lambda-c)\left[4 k t-\beta^{2}\right]^{2}+\alpha \kappa}{\left[4 k t\left(4 k t-\beta^{2}\right)-\alpha \beta^{2}\left(8 k t-\beta^{2}\right)\right]^{2}} \lessgtr 0
$$

where 


$$
\begin{array}{r}
\kappa:=\alpha \beta^{6}+k \beta^{4}(\lambda+\bar{U}(\alpha+1))+6 k t \alpha \beta^{2}\left(4 k t-\beta^{2}\right) \\
+k(c-T)\left(16 k^{2} t^{2}-\beta^{4}(1+\alpha)\right)+4 k^{2} t\left(2 \bar{U}\left(2 k t-\beta^{2}\right)-t \beta^{2}\right)
\end{array}
$$

Proposition 2 (i) If $\alpha=0$, more competition unambiguously increase the quality of the public provider. (ii) In the presence of altruism, the relationship between the quality provision of the public provider and competition is generally ambiguous.

Proof. (i) If $\alpha=0$, the numerator in (13) reduces to $-\beta(T+\lambda-c)$, which is negative because $p_{1}>c$. (ii) The statement in the proposition is true if the sign of the numerator in (13) is ambiguous. Notice that the numerator is monotonically decreasing in $\lambda, \frac{\partial()}{\partial \lambda}=-4 k\left(\left(4 k t-\beta^{2}\right)^{2}+\alpha \beta^{4}\right)<0$. On one hand, setting $\lambda=\underline{\lambda}$, the numerator $\mathrm{L}$ in (13) reduces to

$$
\begin{aligned}
& L=4 \beta \alpha\left(4 k^{2} t^{2} \beta^{2}-k \bar{U}\left(4 k t-\beta^{2}\right)^{2}-k\left(16 k^{2} t^{2}-\alpha \beta^{4}\right)(c-T)\right. \\
& \left.-\alpha \beta^{2}\left(\beta^{4}+6 k t\left(4 k t-\beta^{2}\right)+k \bar{U} \beta^{2}\right)\right)
\end{aligned}
$$

$\mathrm{L}$ is negative if $\beta$ is sufficiently small. Due to monotonicity, $\frac{\partial q_{1}^{*}}{\partial t}<0$ if $\beta$ is sufficiently low for all $\lambda \in(\underline{\lambda}, \bar{\lambda})$. On the other hand, for a sufficiently high $\beta$, setting $\beta$ at the highest level compatible with equilibrium existence, given by $\beta^{2} \rightarrow 4 k t$, L reduces to: $-16 k^{3} t^{2}[c-T-t+\alpha(4 t+T-c+\bar{U})]$. It is positive if $\alpha$ is sufficiently small. Thus, for small $\alpha$, $\frac{\partial q_{1}^{*}}{\partial t}>0$ if $\beta$ is sufficiently high and $\lambda$ is sufficiently low. However, setting $\lambda=\bar{\lambda}$, the numerator L reduces to:

$$
L=\frac{4}{\beta}\left[4 k t\left(4 k t-\beta^{2}\right)-\alpha \beta^{2}\left(8 k t-\beta^{2}\right)\right]\left[\alpha \beta^{2}\left(3 k t-\beta^{2}\right)-k\left(4 k t-\beta^{2}\right)(t-c+T)\right]
$$

The left square bracket is positive while the second one bracket is negative if $\beta$ is sufficiently high. Thus, $\frac{\partial q_{1}^{*}}{\partial t}<0$ if $\beta$ and $\lambda$ are sufficiently high regardless 
of $\alpha$.

The intuition is straightforward in the first part of Proposition 2 . When it is more costly for consumers to travel, they have greater dis-utility from demanding the product from a provider whose location is not ideal. Thus, less competition intensity lower the gains in terms of demand from quality improvements. For a given price $\left(p_{1}\right)$ greater than the marginal cost of production (c), a higher $t$ dampens the incentives to supply more quality provision $\left(\frac{\partial q_{1}^{*}}{\partial t}<0\right)$. This confirms the standard positive direct relation between the competition intensity and quality for a given price.

The effect of competition on the quality of the public provider is ambiguous in the presence of altruism. On one side, an inverse relation between competition and quality persists $\left(\frac{\partial q_{1}^{*}}{\partial t}<0\right)$ if $\beta$ is small or $\lambda$ is large. On the other side, the "reverse result" $\left(\frac{\partial q_{1}^{*}}{\partial t}>0\right)$ corresponds to the following case. Suppose $\alpha$ is small, then $\frac{\partial q_{1}^{*}}{\partial t}>0$ for a parameter set characterized by: (i) sufficiently small profit margin for the public provider (low $\lambda$ ) and (ii) sufficiently large willingness-to-pay for quality (high $\beta$ ). The intuition is as follows. When $\beta$ is sufficiently large, such that competition is sufficiently strong along the quality dimension, the private provider has a strong incentive to increase quality as a response to more competition. When the state subsidy $(\lambda)$ received by the public provider is sufficiently small, the incentive to increase quality is lower for the public provider because the profit margin is low (due to low $\lambda$ ). The last condition corresponds to small altruistic preferences $(\alpha)$ because a high $\alpha$ increases the public provider's marginal payoff of quality provision. The strategic response from the public provider is large enough to dominate (recall that $\frac{\partial q_{1}}{\partial q_{2}}<0$ ), implying that the public provider will respond to increased competition by reducing quality. This holds true if $\alpha$ is strictly positive but not too large. 
For the private provider, the effect of more competition on equilibrium quality is given by:

$$
\begin{gathered}
\frac{\partial q_{2}^{*}}{\partial t}=\beta \frac{4 k\left[\beta^{2}\left(8 k t-\beta^{2}\right)(T+\lambda-c)+4 k t^{2}\left(4 k(c-T)-\beta^{2}\right)\right]-\alpha \Theta}{\left[4 k t\left(4 k t-\beta^{2}\right)-\alpha \beta^{2}\left(8 k t-\beta^{2}\right)\right]^{2}} \lessgtr 0 \\
\Theta:=\beta^{2}\left(5 \alpha \beta^{4}-48 k^{2} t^{2}+4 \bar{U} k \beta^{2}-32 k^{2} t(T+\bar{U}-c)\right. \\
\left.+8 k \beta^{2}(\alpha \bar{U}+\lambda-t-(\alpha+1)(c-T))\right)
\end{gathered}
$$

Proposition 3 (i) If $\alpha=0$, the private provider reduces the quality in response to more competition if $\lambda$ is sufficiently high or $\beta$ is sufficiently low. However, more competition leads to more quality provision for the private provider if $\lambda$ is low and $\beta$ is high. (ii) In the presence of altruism, the private provider has less incentive to increase quality provision in response to more competition.

Proof. (i) The numerator in (14) is monotonically increasing in $\lambda$, setting $\lambda=\bar{\lambda}$ yields $4 k t\left(4 k t-\beta^{2}\right)(T-c+2 t)$, which is positive because $t>c-T$. Therefore, $\frac{\partial q_{2}^{*}}{\partial t}>0$ if $\lambda$ is sufficiently high. However, setting $\lambda=\underline{\lambda}$ yields $4 k t^{2}\left(4 k \lambda-\beta^{2}\right)$ which has an ambiguous sign. It is positive if $\beta$ is sufficiently low. Thus, $\frac{\partial q_{2}^{*}}{\partial t}>0$ if $\beta$ is sufficiently low for all $\lambda \in(\underline{\lambda}, \bar{\lambda})$. On the other hand, for a sufficiently high $\beta$, setting the highest level compatible with equilibrium existence, $\beta^{2} \rightarrow 4 k t$, the numerator in (14) reduces to $16 k^{2} t^{2}(\lambda-t)$, which is negative if $t>\lambda$. Recall that equilibrium existence requires $t>c-T$, which implying $t>\underline{\lambda}:=c-T$. Thus, if $\alpha=0, \frac{\partial q_{2}^{*}}{\partial t}<0$ if $\beta$ is sufficiently high and $\lambda$ is sufficiently small. (ii) The statement is true if $\Theta<0$. Notice that $\Theta$ is monotonically increasing in $\lambda$. Setting $\lambda=\bar{\lambda}$ in $\Theta$ yields 


$$
\Theta=-\beta^{2}\left[8 k t\left(2 k t+\beta^{2}\right)+4 k \bar{U}\left(8 k t-\beta^{2}\right)+5 \alpha \beta^{2}(8 k t-1)\right]<0
$$

Thus, $\Theta<0$ for all $\lambda \in(\underline{\lambda}, \bar{\lambda})$.

The first part of Proposition 3 shows that, if both providers are profitoriented, the indirect effect dominates the direct effect if the regulator transfers a high level of state subsidy $(\lambda)$ to the public provider. A higher $\lambda$ will give more incentive for the public provider to increase quality provision, which, in return reduces the quality for the private provider due to strategic substitutability $\left(\frac{\partial q_{2}\left(q_{1}\right)}{\partial q_{1}}<0\right)$. Likewise, the lower is $\beta$, the less demand responds to quality changes relative to price changes. Thus, if $\beta$ is low, an increase in competition has a relatively larger (smaller) effect on the private provider's incentive to reduce (increase) the price (quality). In both cases, the indirect effect dominates the direct effect $\left(\frac{\partial q_{2}^{*}}{\partial t}>0\right)$, leading to lower quality provision for the private provider as a response to increased competition via the reduction in the price.

What is the effect of competition on $q_{2}^{*}$ if $\beta$ is sufficiently large? In this case, a reduction in $t$ has a larger effect on demand-responsiveness to quality. If the state subsidy $(\lambda)$ received by the public provider is sufficiently small, the private provider might respond to increased competition by choosing a higher level of quality. Notice that the best response function in equation (7) is monotonically increasing in the state subsidy, a lower value of $\lambda$ reduces the public provider's incentives for quality. However, $\frac{\partial q_{2}\left(q_{1}\right)}{\partial q_{1}}<0$ in (8) and this will reduce the negative feedback effect on the private provider's incentives for quality provision. Therefore, if $\beta$ is sufficiently large and $\lambda$ is sufficiently small, the direct effect of competition on the private provider's incentive for quality provision dominates the indirect effect. This leads to higher quality provision in equilibrium. 
The main idea behind the second part of Proposition 3 is that higher $\alpha$ reinforces the public provider to increase quality as a response to more competition (marginal payoff of quality is increasing in $\alpha$ ). Due to strategic substitutability $\left(\frac{\partial q_{2}}{\partial q_{1}}<0\right)$, it will increase the "probability" that the private provider dampens quality provision in response to increased competition.

For the private provider, the effect of more competition on the equilibrium price is given by:

$$
\begin{gathered}
\frac{\partial p_{2}^{*}}{\partial t}=2 k \frac{16 k^{2} t^{2}\left(2 t\left(2 k t-\beta^{2}\right)+\lambda \beta^{2}\right)+\alpha \varrho}{\left[4 k t\left(4 k t-\beta^{2}\right)-\alpha \beta^{2}\left(8 k t-\beta^{2}\right)\right]^{2}} \\
\varrho:=\beta^{2}\left(\alpha \beta^{4}(c-T)-\beta^{4} \lambda+10 \alpha t \beta^{2}\left(4 k t-\beta^{2}\right)\right. \\
\left.+32 k t^{2}\left(\beta^{2}-2 k t\right)+(c-T)\left(4 k t-\beta^{2}\right)^{2}+\bar{U}\left(16 k^{2} t^{2}-\alpha \beta^{4}\right)\right)
\end{gathered}
$$

Proposition 4 (i) If $\alpha=0$, the private provider reduces the price in response to more competition if $\lambda$ is sufficiently high or $\beta$ is sufficiently low. However, more competition leads to higher price for the private provider if $\lambda$ is low and $\beta$ is high. (ii) The scope for a price reduction by the private provider in response to more competition is larger in the presence of altruism.

Proof. (i) If $\alpha=0$, the numerator in (15) reduces to: $2 t\left(2 k t-\beta^{2}\right)+\lambda \beta^{2}$. It is monotonically increasing in $\lambda$, setting $\lambda=\bar{\lambda}$ yields $2 k(T-c+2 t)$, which is positive because $t>c-T$. Therefore, $\frac{\partial p_{2}^{*}}{\partial t}>0$ if $\lambda$ is sufficiently high. However, setting $\lambda=\underline{\lambda}$ yields $2 k\left[\beta^{2}(c-T)+2 t\left(2 k t-\beta^{2}\right)\right]$ which has an ambiguous sign. It is positive if $\beta$ is sufficiently low. Thus, $\frac{\partial p_{2}^{*}}{\partial t}>0$ if $\beta$ is sufficiently low for all $\lambda \in(\underline{\lambda}, \bar{\lambda})$. On the other hand, for a sufficiently high $\beta$, 
setting the highest level compatible with equilibrium existence, $\beta^{2} \rightarrow 4 k t$, the numerator in (15) reduces to $-4 k t(t-\lambda)$, which is negative if $t>\lambda$. Recall that equilibrium existence requires $t>c-T$, which implying $t>\underline{\lambda}:=c-T$. Thus, if $\alpha=0, \frac{\partial p_{2}^{*}}{\partial t}<0$ if $\beta$ is sufficiently high and $\lambda$ is sufficiently small. (ii) The statement is true if $\varrho>0$. Notice that $\varrho$ is monotonically decreasing in $\lambda$. Setting $\lambda=\bar{\lambda}$ in $\varrho$ yields

$$
\begin{gathered}
\varrho=\beta^{2}\left(\bar{U}\left(4 k t-\beta^{2}\right)\left(\beta^{2}+4 k t\right)-4 k t^{2}\left(16 k t-7 \beta^{2}\right)\right. \\
\left.+k t\left(3 \beta^{2}+16 k t\right)(c-T)+\alpha \beta^{2}\left(5 t\left(8 k t-\beta^{2}\right)+\bar{U} \beta^{2}\right)\right)
\end{gathered}
$$

Due to monotonicity, $\varrho>0$ for all $\lambda \in(\underline{\lambda}, \bar{\lambda})$ if $\beta$ is sufficiently high.

The results presented in Proposition 4 lay in the role of consumers' marginal willingness-to-pay for quality. If $\beta$ is high and $\lambda$ is low, then direct effect dominates the indirect effect (c.f Proposition 3). This implies that the private provider has incentive to increase the quality provision as a response for increased competition. Thus, lower $t$ makes demand more quality elastic and less price elastic. This leads the price $\left(p_{2}\right)$ to be higher in equilibrium (because quality and price are complementary strategies for the private). If $\beta$ is low, demand responds more to the price relative to quality. Therefore, more competition intensity (lower $t$ ) yields a stronger incentive to decrease the price of the private provider if consumer's willingness-to-pay for quality is sufficiently low, and to increase $p_{2}$ if $\beta$ is high and $\lambda$ is low. 


\subsubsection{Average Quality}

In this section, we evaluate whether the average quality will increase in response to more competition. When both providers are profit oriented, under certain conditions, the indirect effect dominates the direct effect for the private provider $\left(\frac{\partial q_{2}^{*}}{\partial t}>0\right)$ while more competition always gives an incentive for the public provider to increase quality provision in equilibrium. It is necessary to assess the effect of competition on overall quality (weighted average quality) due to two counteracting forces $\left(\frac{\partial q_{1}}{\partial t}<0\right.$ and $\left.\frac{\partial q_{2}}{\partial t}>0\right)$. If $\alpha=0$, given the equilibrium levels, the weighted average quality $\left(\bar{q}=D_{1}\left(q_{1}^{*}, q_{2}^{*}, p_{2}^{*}\right) * q_{1}^{*}+D_{2}\left(q_{1}^{*}, q_{2}^{*}, p_{2}^{*}\right) * q_{2}^{*}\right)$ is given by

$$
\bar{q}=\beta \frac{4 k^{2} t^{2}(t-5(c-T))+3 k t \lambda\left(4 k t-3 \beta^{2}\right)+\Gamma}{4 k t\left(4 k t-\beta^{2}\right)^{2}}
$$

where $\Gamma=\beta^{2} \lambda\left(\beta^{2}+k \lambda\right)+(c-T)\left[\beta^{2}\left(9 k t-\beta^{2}\right)+k \lambda\left(4 k t-\beta^{2}\right)\right]$

In order to assess if the market has higher average quality with increased competition (resulting in more winners than losers), we differentiate $(\bar{q})$ over the competition intensity $(t)$ which yields

$$
\frac{\partial \bar{q}}{\partial t}=\beta \frac{-\beta^{2} \lambda\left(12 k t-\beta^{2}\right)\left(\beta^{2}+k \lambda\right)-4 k^{2} t^{2}\left(2 t \beta^{2}+3 \lambda\left(4 k t-5 \beta^{2}\right)\right)+\wp}{4 k t^{2}\left(4 k t-\beta^{2}\right)^{3}}
$$

where $\wp=(c-T)\left(4 k t-\beta^{2}\right)\left(20 k^{2} t^{2}-\left(\beta^{2}+k \lambda\right)\left(8 k t-\beta^{2}\right)\right)$

Proposition 5: If providers are profit-oriented, overall quality increases in response to more competition if consumers' marginal willingness-to-pay for quality $(\beta)$ is sufficiently high. However, for a sufficiently low willingness-topay for quality, increased competition reduces the average quality if the state subsidy $(\lambda)$ received by the public provider is sufficiently small. 
Proof: The sign of (17) is determined by the sign of the numerator. If $\beta$ is sufficiently high, setting $4 k t \rightarrow \beta^{2}$, the numerator reduces to $-32 k^{3} t^{2}(t-$ $\lambda)^{2}<0$. Thus, $\frac{\partial \bar{q}}{\partial t}<0$ if $\beta$ is sufficiently high. The partial derivative of the numerator with respect to $\lambda$ yields

$$
\begin{array}{r}
\frac{\partial()}{\partial \lambda}=\left(-\beta^{4}\left(12 k t-\beta^{2}\right)-12 k^{2} t^{2}\left(4 k t-5 \beta^{2}\right)-2 k \beta^{2} \lambda\left(12 k t-\beta^{2}\right)\right. \\
\left.-k(c-T)\left(4 k t-\beta^{2}\right)\left(8 k t-\beta^{2}\right)\right)
\end{array}
$$

$\frac{\partial()}{\partial \lambda}<0$ if $\beta$ is sufficiently low. In this case, the numerator is monotonically decreasing in $\lambda$. Otherwise, for sufficiently high $\beta$, setting $4 k t \rightarrow$ $\beta^{2}$, reduces to: $64 k^{3} t^{2}(t-\lambda)$ which has an ambiguous sign. It is positive (negative) if $t>\lambda(t<\lambda)$. Setting $\lambda=\bar{\lambda}$ in the numerator yields $\frac{4 k t}{\beta^{2}}\left(4 k t-\beta^{2}\right)^{2}(T-c+t)\left(\beta^{2}+k(c-T-6 t)\right)<0$ regardless if $\beta$ is high or low. On the other hand, setting $\lambda=\underline{\lambda}$ yields $8 k^{2} t^{2}(T-c+t)\left(4 k(c-T)-\beta^{2}\right) \lessgtr 0$. It is positive if $\beta$ is sufficiently low. Thus, $\frac{\partial \bar{q}}{\partial t}>0$ if $\beta$ and $\lambda$ are sufficiently small.

The intuition is simple. A reduction in $t$ has a larger effect on demandresponsiveness to quality the larger $\beta$ is. Thus, the intensity of quality competition is strong when consumer's marginal willingness-to-pay for quality is high. Both providers will have a strong incentive to increase quality as a response to more competition. In sum, this leads to higher average quality. On the contrary, if $\beta$ is low, the private provider will reduce quality in response to increased competition (c.f Proposition 3). Moreover, the role of state subsidy $(\lambda)$ is essential to the profit margin for the public provider. If $\lambda$ is low, the public provider has weak incentives for quality incentives due to tight profit margin. Hence, a reduction in quality for the private provider (because the indirect effect dominates the direct effect $\frac{\partial q_{2}}{\partial t}>0$ ) outweighs 
weak incentive (small positive effect) for the public provider. The overall effect, though, is a decrease in the equilibrium average quality in response to increased competition.

In the presence of altruism, the function is so tedious. In the Appendix, we provide a numerical example to tackle the effect of competition on average quality if $\alpha>0$. We encounter, given the space restrictions, that average quality increases in response to more competition if the direct effect dominates the indirect effect.

\subsection{Key Policy Instruments - Regulatory Tools}

In this section, we analyze the role of the social planner who controls the regulatory tools: state subsidy and copayment fees. Thus, we study the effect of an increase in each of the key policy instruments on the equilibrium quality and price levels. How do regulatory tools affect quality competition and average quality under profit orientation or altruistic preferences?

\subsubsection{State Subsidy}

As before, we differentiate equilibrium levels over the key policy instrument, $\lambda$. The comparative statics results are given by:

$$
\begin{gathered}
\frac{\partial q_{1}^{*}}{\partial \lambda}=\beta \frac{\left(4 k t-\beta^{2}\right)}{4 k t\left(4 k t-\beta^{2}\right)-\alpha \beta^{2}\left(8 k t-\beta^{2}\right)}>0 \\
\frac{\partial q_{2}^{*}}{\partial \lambda}=-\frac{\beta^{3}}{4 k t\left(4 k t-\beta^{2}\right)-\alpha \beta^{2}\left(8 k t-\beta^{2}\right)}<0 \\
\frac{\partial p_{2}^{*}}{\partial \lambda}=-2 k t \frac{\beta^{2}}{4 k t\left(4 k t-\beta^{2}\right)-\alpha \beta^{2}\left(8 k t-\beta^{2}\right)}<0
\end{gathered}
$$


Proposition 6: Whether the public provider is motivated or not, an increase in state subsidy leads to higher quality for the public provider and lower quality and price for the private provider.

The degree of altruism $(\alpha)$ does not enter in (18-20), the responsiveness of equilibrium levels for both providers to the state subsidy will not change whether they are profit-oriented or in the presence of altruistic preferences. The quality of the public provider is increasing in the state subsidy. This is intuitive with the constant marginal costs. The public provider benefits from an increase in price-cost margin, it can invest more in quality improvements. Thus, a high amount of state subsidy translates to higher $q_{1}$ which, in return, leads to lower $q_{2}$ due to strategic substitution (recall best response functions). The private provider reduces the price, $p_{2}$ due to complementary strategic interaction with $q_{2}$. Along counteracting effects $\left(\frac{\partial q_{1}^{*}}{\partial \lambda}>0\right.$ and $\left.\frac{\partial q_{2}^{*}}{\partial \lambda}<0\right)$, does more state subsidy increase average quality in equilibrium? Differentiating average quality (in the presence of altruism) with respect to $\lambda$ yields

$$
\frac{\partial \bar{q}_{\alpha}}{\partial \lambda}=\beta \frac{4 k t\left[3 k t\left(4 k t-3 \beta^{2}\right)+\beta^{2}\left(\beta^{2}+2 k \lambda\right)+k(c-T)\left(4 k t-\beta^{2}\right)\right]+\alpha \Delta}{\left[4 k t\left(4 k t-\beta^{2}\right)-\alpha \beta^{2}\left(8 k t-\beta^{2}\right)\right]^{2}}
$$

where $\Delta=\beta^{2}\left[\beta^{2}\left(13 k t-\beta^{2}\right)+8 k^{2} t \bar{U}-(c-T) k \beta^{2}\right]$

Proposition 7: (i) If $\alpha=0$, average quality is increasing in state subsidy if $\beta$ is sufficiently low. However, average quality decreases in response to more state subsidy if $\beta$ is sufficiently large and $\lambda$ is sufficiently small. (ii) In the presence of altruism, the scope for more average quality is larger if $\beta$ is sufficiently low. 
Proof: (i) The numerator in (21) is positive if $\beta$ is low. Thus, $\frac{\partial \bar{q}}{\partial \lambda}>0$. However, for a sufficient large $\beta$, setting $\beta^{2} \rightarrow 4 k t$, reduces (21) to: $-8 k^{2} t(t-\lambda)$, which is negative if $t>\lambda$. Recall that $t>\underline{\lambda}:=c-T$. Hence, $\frac{\partial \bar{q}}{\partial \lambda}<0$ if $\beta$ is high and $\lambda$ is small. (ii) The statement is true if $\Delta$ is positive. If the value of $\beta$ is sufficiently small, $\Delta>0$.

The amount of state subsidy determines the market shares of the two providers. A high $\lambda$ has a positive impact on public provider's incentive to offer more quality provision and thus lead to an inflow of consumers (market share expansion). On the contrary, due to strategic interaction $\left(\frac{\partial q_{2}}{\partial q_{1}}<0\right)$, there is a negative effect on the private provider where the strength of the strategic response depends on consumer's marginal willingness-to-pay for quality, $\beta$. It is stronger (weaker) if $\beta$ is large (small). If $\beta$ is sufficiently low, an increase in $\lambda$ will cause the reduction in $q_{2}$ to be relatively small in comparison to the increase in $q_{1}$. In sum, this leads to higher average quality. On the contrary, if $\beta$ is sufficiently high, the reverse result requires $\lambda$ to be sufficiently small. Suppose $\lambda$ is sufficiently small, the market share of the private provider is sufficiently high such that the reduction in $q_{2}$ outweighs the rise in $q_{1}$ and yields a lower average quality in response to more state subsidy. Notice that the marginal revenue of quality for the public provider increases in the presence of altruism. Thus, the superiority of the positive effect (due to increase in $q_{1}$ ) over the negative one (due to reduction in $q_{2}$ ) leads to more average quality, but only if $\beta$ is sufficiently low.

\subsubsection{Co-payment Fees}

The growing interest in raising the co-payment reflects a desire to simulate market-like behavior in regulated markets. The marginal effect of an increase in co-payment on equilibrium levels is obtained by differentiating 


$$
\begin{aligned}
\frac{\partial q_{1}^{*}}{\partial T} & =\beta \frac{4 k t(1-\alpha)-\beta^{2}}{4 k t\left(4 k t-\beta^{2}\right)-\alpha \beta^{2}\left(8 k t-\beta^{2}\right)} \gtrless 0 \\
\frac{\partial q_{2}^{*}}{\partial T} & =\beta \frac{4 k t-\beta^{2}(1+\alpha)}{4 k t\left(4 k t-\beta^{2}\right)-\alpha \beta^{2}\left(8 k t-\beta^{2}\right)}>0 \\
\frac{\partial p_{2}^{*}}{\partial T} & =2 k t \frac{4 k t-\beta^{2}(1+\alpha)}{4 k t\left(4 k t-\beta^{2}\right)-\alpha \beta^{2}\left(8 k t-\beta^{2}\right)}>0
\end{aligned}
$$

Proposition 8: (i) If $\alpha=0$, all equilibrium levels unambiguously increase in response to more co-payment fees. (ii) If $\alpha>0$, higher co-payment leads to higher quality and price for the private provider, on the contrary, the effect of higher co-payment on the quality of the public provider is positive (negative) if the degree of altruism is sufficiently small (large).

Proof. (i) If $\alpha=0$, all equilibrium levels $\left(q_{1}^{*}, q_{2}^{*}, p_{2}^{*}\right)$ increase in $\mathrm{T}$ where $\frac{\partial q_{1}^{*}}{\partial T}=\frac{\partial q_{2}^{*}}{\partial T}=\frac{\beta}{4 k t}$ and $\frac{\partial p_{2}^{*}}{\partial T}=\frac{1}{2}$. In the presence of altruism, (ii) the numerator in (22) is monotonically decreasing in $\alpha$. Setting the highest level of altruism $(\alpha=\bar{\alpha})$, reduces the numerator in $(22)$ to: $:-\frac{\left(4 k t-\beta^{2}\right)^{3}}{\beta^{2}\left(8 k t-\beta^{2}\right)}$ which is negative. Hence, $\frac{\partial q_{1}^{*}}{\partial T}<0$ if $\alpha$ is sufficiently high. However, $\frac{\partial q_{1}^{*}}{\partial T}>0$ if $\alpha$ is sufficiently small. Thus, the sign is ambiguous and depends on the degree of altruism. Both equations (23) and (24) share the same numerator. Setting the highest level of altruism $(\alpha=\bar{\alpha})$, reduces the numerator in $(23)$ to: $\frac{\left(4 k t-\beta^{2}\right)^{2}}{\left(8 k t-\beta^{2}\right)}$, which is positive. Thus, $\frac{\partial q_{2}^{*}}{\partial T}>0$ and $\frac{\partial p_{2}^{*}}{\partial T}>0$ for all $\alpha \in(\underline{\alpha}, \bar{\alpha})$.

If both providers are profit maximisers, the regulator can induce both providers to increase quality provision through an increase in the co-payment fees. Price regulation for the public provider is equivalent to regulating mark-ups. Thus, a higher $\mathrm{T}$ has a direct positive impact on the profit margin of the public provider which leads to higher $q_{1}$. Furthermore, all else equal, higher 
T increases the demand for the private provider (c.f Equation (2)), which makes the demand for this provider less price-elastic. Thus, the provider optimally responds by increasing the price $\left(p_{2}\right)$. Based on Equation (6), both price and quality of the private provider are complementary strategies, this will lead to higher quality, $q_{2}$. The intuition for the second part of the proposition entails the trade-off effect on the public provider's incentive for quality provision in response to more co-payment fees. In the presence of altruism, $\alpha>0$, there is an additional strategic response $\left(\frac{\partial q_{1}\left(q_{2}\right)}{\partial q_{2}}<0\right)$. A higher quality for the private provider as a response to higher $\mathrm{T}$ leads to lower quality for the public, and this effect is sufficiently strong only if $\alpha$ is large enough.

If $\alpha=0$, an increase in $\mathrm{T}$ induces both providers to increase quality provision. Is it clear-cut to draw a conclusion for a higher average quality in equilibrium? Besides, the average quality might increase or decrease depending on the dominant effect $\left(\frac{\partial q_{2}^{*}}{\partial T}>0\right.$ vs. $\left.\frac{\partial q_{1}^{*}}{\partial T}<0\right)$. We examine the effect of the copayment fees on the average quality which is given by

$$
\frac{\partial \bar{q}_{\alpha}}{\partial T}=\beta \frac{4 k t\left(4 k t-\beta^{2}\right)\left(5 k t-\beta^{2}-k \lambda\right)+\alpha \Xi}{\left[4 k t\left(4 k t-\beta^{2}\right)-\alpha \beta^{2}\left(8 k t-\beta^{2}\right)\right]^{2}}
$$

where $\Xi=2 k\left(4 k t-\beta^{2}\right)\left(4 k t-\beta^{2}(1+\alpha)\right)(T-c)-4 k^{2} t \bar{U}\left(4 k t-\beta^{2}\right)+\beta^{4}(13 k t-$ $\left.\beta^{2}\right)-16 k^{2} t^{2}\left(6 k t+\beta^{2}\right)+k \beta^{4} \lambda+k \alpha \beta^{2}\left(24 k t^{2}+\bar{U} \beta^{2}+2 t \beta^{2}\right)$

Proposition 9: (i) If $\alpha=0$, average quality is increasing in the co-payment if $\lambda$ is sufficiently low. However, for a sufficiently large $\lambda$, a higher copayment leads to a higher (lower) average quality provision if $\beta$ is sufficiently large (small). (ii) The presence of public provider altruism increases the scope for a negative relationship between co-payment and average quality. 
Proof (i) If $\alpha=0$, the numerator in (25) reduces to $5 k t-\beta^{2}-k \lambda$, which is monotonically decreasing in $\lambda$. Setting $\lambda=\underline{\lambda}$ yields: $k(4 t+t-(c-T))-\beta^{2}$, which is positive. Thus, $\frac{\partial \bar{q}_{\alpha}}{\partial T}>0$ if $\lambda$ is sufficiently low. On the other hand, setting $\lambda=\bar{\lambda}$ yields $\left(4 k t-\beta^{2}\right) \frac{\beta^{2}-k(T-c+t)}{\beta^{2}}$ which has an ambiguous sign. It is positive (negative) if $\beta$ is sufficiently high (low). Thus, for sufficiently high $\lambda, \frac{\partial \bar{q}_{\alpha}}{\partial T}>(<) 0$ if $\beta$ is sufficiently high (low). (ii) The statement is true if $\Xi<0$. Notice that $\Xi$ is monotonically increasing in $\lambda\left(\frac{\partial \Xi}{\partial \lambda}=k \beta^{4}>0\right)$. Setting $\lambda=\bar{\lambda}$ in $\Xi$ yields

$$
\begin{aligned}
& \Xi=\beta^{4}\left(13 k t-\beta^{2}\right)+3 k t \alpha \beta^{2}\left(8 k t-\beta^{2}\right)+k \alpha \beta^{2}\left(8 k t-\beta^{2}\right)(c-T)-12 k^{2} t^{2}\left(8 k t-\beta^{2}\right)- \\
& 4 k^{2} t \bar{U}\left(4 k t-\beta^{2}\right)-k\left(8 k t-\beta^{2}\right)\left(4 k t-\beta^{2}\right)(c-T)
\end{aligned}
$$

Thus, $\Xi<0$ for all $\lambda \in(\underline{\lambda}, \bar{\lambda})$ if $\beta$ is sufficiently small.

The first part of Proposition 9 shows that average quality might go down although both quality levels will increase in response to higher $T$ if $\beta$ is small and $\lambda$ is large. The reason is that a higher co-payment fees leads to reallocation of consumers from the public to the private provider. If $\lambda$ is sufficiently high, $q_{1}>q_{2}$ (cf Proposition 1). Hence, the public provider is the highquality provider. If $\beta$ is small, a large share of consumers choose low-quality provider. Thus, a reallocation of consumers from the public to the private provider can cause average quality to drop even if quality increases for both providers. The intuition for the second part is as follows. The scope for less quality provision by the public provider in response to increased co-payment fees is larger if $\alpha>0$ (cf. Proposition 7). Thus, in the presence of altruism, an increase in $T$, will increase the "probability" that the market has lower average quality.

The policymaker has to pinpoint what determines the relative strength on quality provision of the two counteracting effects, namely, an increase in both 
key policy instruments. If $\alpha=0$, for the public provider we have $\frac{\partial q_{1}^{*}}{\partial T}>0$ and $\frac{\partial q_{1}^{*}}{\partial \lambda}>0$ whereas opposite effects appear for the private provider: $\frac{\partial q_{2}^{*}}{\partial T}>0$ and $\frac{\partial q_{2}^{*}}{\partial \lambda}<0$. If $\alpha>0$, the public provider has a trade off between regulatory tools if he has high altruistic preferences: $\frac{\partial q_{1}^{*}}{\partial T}<0$ and $\frac{\partial q_{1}^{*}}{\partial \lambda}>0$.

\subsubsection{Share of Co-payment}

In previous subsections, we consider the effect on quality provision when co-payment or state subsidy varies. Increase in one of the key policy instruments will definitely lead to an increase in the total price, $p_{1}$, facing the public provider. More relevant policy would be to fix the price for the public provider but we change the share of costs paid by the consumers (co-payment) relative to the share paid by the regulator (as state subsidy). Based on the utility function of the consumer (equation 1 ), we assume $T=s p_{1}$ where $s$ is the share of co-payment. In this scenario, $\lambda=(1-s) p_{1}$ and the total price, $p_{1}=T+\lambda$, is fixed. We solve the model as before using two-stage game. If the Subgame Perfect Nash Equilibrium is an interior solution, the equilibrium outcome is given by

$$
\begin{gathered}
q_{1}^{s}=\beta \frac{\left(p_{1}-c\right)\left(4 k t-\beta^{2}\right)+\alpha\left(\bar{U}\left(4 k t-\beta^{2}\right)+4 t\left(3 k t-\beta^{2}+k\left(c-s p_{1}\right)\right)\right)}{4 k t\left(4 k t-\beta^{2}\right)-\alpha \beta^{2}\left(8 k t-\beta^{2}\right)} \\
q_{2}^{s}=\beta \frac{\left(s p_{1}-c\right)\left(4 k t-\beta^{2}\right)+4 k t^{2}-\beta^{2}(1-s) p_{1}-\alpha\left(\beta^{2}\left(s p_{1}+5 t+\bar{U}-c\right)\right)}{4 k t\left(4 k t-\beta^{2}\right)-\alpha \beta^{2}\left(8 k t-\beta^{2}\right)}
\end{gathered}
$$


$p_{2}^{s}=\frac{2 k t\left(\left(4 k t-\beta^{2}\right)\left(s p_{1}+c\right)+4 k t^{2}-\beta^{2}(1-s) p_{1}\right)-\alpha\left(\beta^{2}\left(2 k t\left(s p_{1}+\bar{U}+5 t\right)+c\left(6 k t-\beta^{2}\right)\right)\right)}{4 k t\left(4 k t-\beta^{2}\right)-\alpha \beta^{2}\left(8 k t-\beta^{2}\right)}$

We differentiate equilibrium levels (Equations (26-28)) with respect to the share of co-payment, $s$, which are given by

$$
\begin{gathered}
\frac{\partial q_{1}^{s}}{\partial s}=-4 k t \alpha \beta \frac{p_{1}}{4 k t\left(4 k t-\beta^{2}\right)-\alpha \beta^{2}\left(8 k t-\beta^{2}\right)} \leq 0 \\
\frac{\partial q_{2}^{s}}{\partial s}=\beta \frac{p_{1}\left(4 k t-\alpha \beta^{2}\right)}{4 k t\left(4 k t-\beta^{2}\right)-\alpha \beta^{2}\left(8 k t-\beta^{2}\right)}>0 \\
\frac{\partial p_{2}^{s}}{\partial s}=\frac{2 k t p_{1}\left(4 k t-\alpha \beta^{2}\right)}{4 k t\left(4 k t-\beta^{2}\right)-\alpha \beta^{2}\left(8 k t-\beta^{2}\right)}>0
\end{gathered}
$$

Proposition 10: (i) If $\alpha=0$, the quality of the public provider is indifferent to change in the share of co-payment, s, on the contrary, both the quality and price of the private provider are increasing in $s$ (ii) If $\alpha>0$, higher share of co-payment leads to higher quality and price for the private provider, however, the relationship is negative for the public provider.

Proof. (i) If $\alpha=0$, equations (29-31) are reduced to: $\frac{\partial q_{1}^{s}}{\partial s}=0, \frac{\partial q_{2}^{s}}{\partial s}=$ $\beta \frac{p_{1}}{4 k t-\beta^{2}}>0$, and $\frac{\partial p_{2}^{s}}{\partial s}=2 k t \frac{p_{1}}{4 k t-\beta^{2}}>0$ respectively. (ii) If $\alpha>0$, it follows immediately from equations (29-31) that the relation is negative between $s$ and $q_{1}^{s}$ while it is positive with respect to $q_{2}^{s}$ and $p_{2}^{s}$ respectively (second order conditions are satisfied, recall $\left.2 k t>\alpha \beta^{2}\right)$.

The first part of Proposition 10 shows that if consumers face higher copayment fees (as costs paid out of their pockets) relative to the share paid 
by the regulator in terms of state-subsidy (lower $\lambda$ ), this has no effect on the quality for the public provider. An increase in $s$ does not increase the profit margin of the public provider as the total price is fixed. However, all else equal, higher $s$ (which means higher $T$ ) increases the demand for the private provider (equation (2)), which makes the demand for this provider less price-elastic. This will, in turn, lead to higher quality (because price and quality are complementary strategies).

In the presence of altruism, there is an additional strategic response $\left(\frac{\partial q_{1}^{s}}{\partial q_{2}^{s}}<0\right)$. A higher quality for the private provider in response to higher $s$ leads to lower quality for the public, and this effect holds regardless of the motivation level (i.e degree of $\alpha$ ) in contrast to Proposition 8.

If the policymaker reduces the state-subsidy per consumer (i.e higher $s$ ), how does this affect the quality provision in equilibrium? We examine the effect of higher share of co-payment on the average quality, which is given by

$$
\frac{\partial \bar{q}_{\alpha}^{s}}{\partial s}=\beta \frac{4 k^{2} t p_{1}\left(8 k t\left(t+s p_{1}\right)+\beta^{2}\left(c-p_{1}\right)-4 k t\left(c+p_{1}\right)\right)-k \alpha p_{1} \Psi}{\left(\alpha \beta^{4}+16 k^{2} t^{2}-4 k t \beta^{2}-8 k t \alpha \beta^{2}\right)^{2}} \lessgtr 0
$$

where $\Psi=\left(\beta^{4}\left(c-p_{1}\right)+2\left(8 k t\left(2 k t-\beta^{2}\right)-\alpha \beta^{4}\left(c-p_{1}\right)^{2}\left(4 k t-\beta^{2}\right)\right)\left(c-s p_{1}\right)+\right.$ $\left.\left(4 k t-\alpha \beta^{2}\right)\left(24 k t^{2}+\bar{U} \beta^{2}\right)+2 t\left(\beta^{2}\left(8 k t-\alpha \beta^{2}\right)+8 k^{2} t \bar{U}\right)\right)$

Proposition 11: (i) If $\alpha=0$, average quality decreases (increases) in response to a higher share of co-payment for a sufficiently large (small) amount of state subsidy. (ii) The presence of altruism reduces the scope for a positive relationship between average quality and the share of co-payment.

Proof. (i) If $\alpha=0$, equation (32) reduces to: 


$$
\frac{\partial \bar{q}^{s}}{\partial s}=\frac{1}{4} \beta p_{1} \frac{8 k t\left(t+s p_{1}\right)+\beta^{2}\left(c-p_{1}\right)-4 k t\left(c+p_{1}\right)}{t\left(4 k t-\beta^{2}\right)^{2}}
$$

The numerator in $\frac{\partial \bar{q}}{\partial s}$ can be written as: $8 k t\left(t+s p_{1}\right)+\beta^{2}\left(c-\lambda-s p_{1}\right)-4 k t(c+$ $\left.\lambda+s p_{1}\right)$ where $\lambda=(1-s) p_{1}$. This term is decreasing in $\lambda\left(\frac{\partial()}{\partial \lambda}=-\left(\beta^{2}+4 k t\right)<\right.$ $0)$. Setting $\lambda=\underline{\lambda}: c-s p_{1}$, reduces the expression to: $8 k t\left(t+s p_{1}-c\right)>0$ (recall $\left.t>c-s p_{1}\right)$. Thus, if $\lambda$ is sufficiently small, $\frac{\partial \bar{q}}{\partial s}>0$. However, setting $\lambda=\bar{\lambda}: \frac{\left(4 k t-\beta^{2}\right)\left(s p_{1}-c\right)+4 k t^{2}}{\beta^{2}}$, the expression reduces to: $4 k t\left(4 k t-\beta^{2}\right) \frac{c-t-s p_{1}}{\beta^{2}}$, which is negative. Therefore, $\frac{\partial \bar{q}}{\partial s}<0$ if $\lambda$ is sufficiently high. (ii) If $\alpha>0$, the statement in the proposition is true if $\Psi>0$. Notice that $\Psi$ is decreasing in $\lambda\left(\frac{\partial \Psi}{\partial \lambda}=\beta^{4}\left(4 \alpha\left(4 k t-\beta^{2}\right)\left(c-s p_{1}\right)\left(c-\lambda-s p_{1}\right)-1\right)<0\right)$. On one hand, setting $\lambda=\underline{\lambda}$, then $\Psi$ reduces to: $16 k t\left(2 k t-\beta^{2}\right)\left(c-s p_{1}\right)+$ $\left(4 k t-\alpha \beta^{2}\right)\left(24 k t^{2}+\bar{U} \beta^{2}\right)+2 t\left(\beta^{2}\left(8 k t-\alpha \beta^{2}\right)+8 k^{2} t \bar{U}\right)$ which is positive if $\beta$ is sufficiently low (recall $c>s p_{1}$ ). Furthermore, for a sufficiently high $\beta$, setting $\beta^{2}=4 k t, \Psi$ reduces to: $16 k^{2} t^{2}\left(2\left(t(5-4 \alpha)+s p_{1}-c\right)+\bar{U}(2-\alpha)\right)>0$. Therefore, if $\lambda$ is sufficiently small, then $\Psi>0$. On other hand, setting $\lambda=\bar{\lambda}$ $\left(\bar{\lambda}=\frac{\left(4 k t-\beta^{2}\right)\left(s p_{1}-c\right)+4 k t^{2}-\alpha \beta^{2}\left(s p_{1}-c+5 t+\bar{U}\right)}{\beta^{2}}\right)$ and for sufficiently high $\beta\left(\beta^{2}=4 k t\right)$, $\Psi$ reduces to: $3 t(3-\alpha)-(1+\alpha)\left(c-s p_{1}\right)+2 \bar{U}>0$. Thus, $\Psi>0$ for all $\lambda \in(\underline{\lambda}, \bar{\lambda})$ if $\beta$ is sufficiently high.

The intuition for the first part of the proposition is straightforward. If $\lambda$ is sufficiently low, the private is the high-quality provider. An increase in the share of co-payment gives an incentive for the private provider to increase quality investments (c.f Proposition 10). This leads to increase overall average quality in equilibrium. The reverse result $\left(\frac{\partial \bar{q}^{s}}{\partial s}<0\right)$ requires $\lambda$ to be sufficiently high. In this case, the public provider is the high-quality provider. A reallocation of consumers from the public to the private provider as a response of higher share of co-payment can cause average quality to drop (because a larger share of consumers choose the low-quality provider). 
When the public provider is altruistic $(\alpha>0)$, it increases the scope for a quality reduction by the public provider in response to higher $s$ as there is an additional chain of response $\frac{\partial q_{1}^{s}}{\partial s}<0$ (c.f Proposition 10). For example, if consumer's marginal willingness-to-pay for quality is sufficiently high, the strategic response is strong $\left(\frac{\partial q_{1}^{s}}{\partial q_{2}^{s}}<0\right)$. The decrease in $q_{1}^{s}$ is sufficiently high (compared to the increase in $q_{2}^{s}$ ) such that average quality decreases as a response to a higher share of co-payment.

\section{$5 \quad$ Extensions}

\subsection{Implication for Relocation Incentives}

We examine whether the private provider has an incentive to unilaterally relocate along the Hotelling's line towards the public provider. ${ }^{21}$ Although it is costly to relocate, however, our purpose is solely limited to provide insights on the relocation incentives. ${ }^{22} \mathrm{~A}$ consumer who deals with provider $\mathrm{j}$ enjoys a utility located at $z \in L$ :

$$
U_{j}(z)=\left\{\begin{array}{lll}
\bar{U}+\beta q_{1}-T-t z^{2}, & \text { if } & \text { public } \\
\bar{U}+\beta q_{2}-p_{2}-t(x-z)^{2}, & \text { if } & \text { private }
\end{array}\right.
$$

where $x$ represents the location choice for the private provider. As discussed earlier, the market share for the public provider is based on the consumer

\footnotetext{
${ }^{21}$ The argument of relocation can be justified that the private provider has more flexibility to relocate its entities towards the public provider who has kind of authoritarian regime (who requests many approvals and long procedures due to availability of funds, organization structure, etc..)

${ }^{22}$ There are conceptual problems related to optimal locations as the SPNE does not exit if the location of one provider is endogenous along the whole interval $\mathrm{L}$
} 
who is indifferent buying the product from either provider:

$$
D_{1}=\frac{p_{2}-T-\beta\left(q_{2}-q_{1}\right)+t x^{2}}{2 t x}
$$

Accordingly, with a uniform distribution, the private provider gets the remainder of the consumers: $D_{2}=1-D_{1}$. For the main part of the analysis, we consider the following three-stage game:

- The private provider chooses the location $x$

- Both providers simultaneously choose the quality levels $q_{1}$ and $q_{2}$

- The private provider chooses the price level $p_{2}$

Based on objective functions, we implement backward induction to find the optimal price level for the private provider is given by:

$$
p_{2}=\frac{T+c+\beta\left(q_{2}-q_{1}\right)+t x[2-x]}{2}
$$

All else equal, as $x$ increases toward maximum differentiation $(x=1)$, the optimal price level of the private provider is higher compared to $x=0.5$ for instance. At the second stage, we compute the optimal quality levels for both providers. $^{23}$

If the Subgame Perfect Nash Equilibrium is an interior solution, the equilibrium outcome is given by

$$
q_{1}^{*}=\beta \frac{(T+\lambda-c)\left(4 k t x-\beta^{2}\right)+\alpha \theta}{4 k t x\left(4 k t x-\beta^{2}\right)-\alpha \beta^{2}\left(8 k t x-\beta^{2}\right)}
$$

\footnotetext{
${ }^{23}$ Second order conditions are satisfied for: $2 k t x>\alpha \beta^{2}$ and $4 k t x>\beta^{2}$
} 


$$
q_{2}^{*}=\beta \frac{(T-c)\left(4 k t x-\beta^{2}\right)+4 k t^{2} x^{2}(2-x)-\beta^{2} \lambda-\alpha \phi}{4 k t x\left(4 k t x-\beta^{2}\right)-\alpha \beta^{2}\left(8 k t x-\beta^{2}\right)}
$$

where $\theta=\bar{U}\left(4 k t x-\beta^{2}\right)+4 t x\left(k t x(x+2)-\beta^{2}+k(c-T)\right), \phi=\beta^{2}(T+t x(6-$ $x)+\bar{U}-c)$

The equilibrium price level of the private provider is given by

$$
p_{2}^{*}=\frac{2 k t x\left[\left(4 k t x-\beta^{2}\right)(T+c)+4 k t^{2} x^{2}(2-x)-\lambda \beta^{2}\right]-\alpha \mu}{4 k t x\left(4 k t x-\beta^{2}\right)-\alpha \beta^{2}\left(8 k t x-\beta^{2}\right)}
$$

where $\mu=\beta^{2}\left[2 k t x(T+\bar{U}+t x(6-x))+c\left(6 k t x-\beta^{2}\right)\right]$.

We are interested to find if the private provider has any relocation incentives given the quality levels $\left(q_{1}^{*}, q_{2}^{*}\right)$ and equilibrium price $p_{2}^{*}$. We evaluate this by taking the partial derivative $\frac{\partial \pi_{2}}{\partial x}$ and check the expression if it has a negative or positive sign at $x=1$. Without loss of generality, we assume no altruism in order to simplify our interpretation

$$
\left.\frac{\partial \pi_{2}}{\partial x}\right|_{x=1}=\frac{\left[8 k^{2} t^{3}-(c-T)\left(\beta^{4}+2 k t\left(4 k t-3 \beta^{2}\right)\right)-\beta^{2} \lambda\left(6 k t-\beta^{2}\right)\right][\Psi]}{16 k t^{2}\left(4 k t-\beta^{2}\right)^{2}} \lessgtr 0
$$

where $\Psi=\beta^{2} \lambda+(c-T)\left(4 k t-\beta^{2}\right)-4 k t^{2}$.

Proposition 12: If the public provider is a profit-maximizer, the private provider has an incentive (disincentive) to relocate towards the competitor if $\lambda$ is sufficiently small (large) such that $\lambda<(>) \hat{\lambda}$.

Proof: The sign in equation (39) depends on the sign of of the numerator. We see that $\Psi$ is monotonically increasing in $\lambda$. Setting $\lambda=\bar{\lambda}$, yields $\Psi=0$. Thus, $\Psi<0$ for all $\lambda \in(\underline{\lambda}, \bar{\lambda})$. Multiplying the first square bracket by the negative sign yields $-8 k^{2} t^{3}+(c-T)\left(\beta^{4}+2 k t\left(4 k t-3 \beta^{2}\right)\right)+\beta^{2} \lambda\left(6 k t-\beta^{2}\right)$ 
which is monotonically increasing in $\lambda$. Setting $\lambda=c-T$, reduces the term to: $-8 k^{2} t^{2}(t-(c-T))<0$. On other hand, setting $\lambda=\bar{\lambda}$, yields $4 k t\left(4 k t-\beta^{2}\right)(t-(c-T))>0$. Thus, $\left.\frac{\partial \pi_{2}}{\partial x}\right|_{x=1}<0$ if $\lambda$ is sufficiently small. More explicitly, $\left.\frac{\partial \pi_{2}}{\partial x}\right|_{x=1}<(>) 0$ if

$$
\lambda<(>) \hat{\lambda}:=\frac{8 k^{2} t^{3}-\left(\beta^{4}-2 k t\left(3 \beta^{2}-4 k t\right)\right)(c-T)}{\beta^{2}\left(6 k t-\beta^{2}\right)}
$$

The intuition behind the result in Proposition 12 is as follows. If $\lambda$ is sufficiently large, it gives the public provider stronger incentives for quality investments, which, in turn, leads to market share expansion. A higher $\lambda$ is more likely to yield a lower quality for the private provider (due to strategic substitution, $\left.\frac{\partial q_{2}}{\partial q_{1}}<0\right)$. Obviously, this reduces the revenue gain from sufficiently low market share. Hence, relocation choice of the private provider is determined by the effects on revenues, which, in this case, opt not to move towards the public provider and incur higher costs. The market share is mostly skewed towards the public provider who offers a higher quality $\left(q_{1}>q_{2}\right)$.

On the other hand, if $\lambda$ is sufficiently small, the public provider has weak incentives to provide higher quality, because the profit margin is small. In this case, the private provider is the high-quality provider $\left(q_{2}>q_{1}\right)$ and its market share is sufficiently high. To maximize profits, the private provider tends to relocate unilaterally towards the public provider and steal market shares. The private provider's relocation choice has a positive effect on the intensity of quality competition, and a negative effect on the price level (the private provider offers a lower price compared to maximum differentiation). Although there are explicit costs attributed to unilateral relocation for the private provider, guaranteeing a higher quality provision in a mixed duopoly remains a policy challenge. Accordingly, the regulator can encourage uni- 
lateral relocation incentives if and only if the public provider receives small amount of state subsidy per consumer.

\subsection{Policy-Induced Instrument: Direct Information Pro- vision}

State governments have been encouraging and, in some cases, requiring the publication of qualitative information whether in education or healthcare markets. In education, the publication of university rankings based on different individual measures of performance has become commonplace in the UK, USA and elsewhere. In healthcare markets, the Care Quality Commission, which regulates UK National Health Service -NHS hospitals, actively publicises its website which features comparative information on the quality of hospitals. ${ }^{24}$ Hence, in both sectors, the government allocate resources to collect information on quality indicators and ranking of institutions (league tables). In a model related to informational settings, it was shown that increased patient information is qualitatively equivalent to reduced transportation costs (Brekke et al., 2007).

The main purpose of the publication of qualitative information is to make demand more responsive to quality difference. Increasing disclosure of quality indicators and ranking institutions assist consumers in making choices among services and providers. Thus, consumers are more conducive to select the provider that displays a higher quality level. Although the information available to consumers on providers in regulated markets can hardly be considered complete (or even adequate) in many cases, the consumer cannot easily correct the initial error by switching brands until he finds the best product. For instance, in the higher education market, the student usually buys

\footnotetext{
${ }^{24}$ The Netherlands also has a "Kiesbeter" ("Choose better") website with similar information
} 
one college education. Accordingly, the policy maker can potentially provide better information on the providers to increase competition and thereby drive up quality.

In this section, we depart from considering our spatial competition framework and we sketch our analysis based on the demand function given by Equation (2). Thus, we do not interpret $\beta$ as the consumers' willingness to pay for quality. In this scenario, $\beta$ reflects how much demand responds to quality changes. The rationale behind this is that more direct information provision facilitates consumers to observe and compare the data across the providers. We examine the implication of a policy initiative by the regulator and whether better information will increase the incentives for providers to raise quality. Accordingly, we can analyse how the equilibrium levels $\left(q_{1}^{*}, q_{2}^{*}, p_{2}^{*}\right)$ will react to more available information, namely $\beta$. For simplicity, we consider that both providers seek profit maximisation. ${ }^{25}$ The effect of $\beta$ on the equilibrium quality and price are given by

$$
\begin{gathered}
\frac{\partial q_{1}^{*}}{\partial \beta}=\frac{T+\lambda-c}{4 k t}>0 \\
\frac{\partial q_{2}^{*}}{\partial \beta}=\frac{-\beta^{2} \lambda\left(12 k t-\beta^{2}\right)+4 k t^{2}\left(4 k t+\beta^{2}\right)-(c-T)\left(4 k t-\beta^{2}\right)^{2}}{4 k t\left(\beta^{2}-4 k t\right)^{2}} \lessgtr 0 \\
\frac{\partial p_{2}^{*}}{\partial \beta}=4 k t \beta \frac{(t-\lambda)}{\left(4 k t-\beta^{2}\right)^{2}} \lessgtr 0
\end{gathered}
$$

Proposition 13: If $\alpha=0$, (i) The quality of the public provider is monotonically increasing in the direct information provision. (ii) More available

\footnotetext{
${ }^{25}$ In the Appendix, we provide a numerical example to tackle the effect of increased public reporting on the average quality in the presence of altruism
} 
information leads to higher (lower) private quality provision, if the state subsidy is sufficiently small (large). (iii) The price of the private provider responds positively (negatively) to $\beta$ if the product differentiation is relatively large (small) to the state subsidy.

Proof: If $\alpha=0$, (i) it follows directly from (40) that the numerator is positive as $p_{1}>c$. (ii) The numerator in (41) is monotonically decreasing in $\lambda$. Setting $\lambda=\underline{\lambda}$ the numerator reduces $4 k t\left(\beta^{2}+4 k t\right)(T-c+t)$ which is positive. On other hand, setting $\lambda=\bar{\lambda}$, the numerator reduces $-8 k t\left(4 k t-\beta^{2}\right)(T-c+t)$ which is negative. Thus, $\frac{\partial q_{2}^{*}}{\partial \beta}>(<) 0$ if $\lambda$ is sufficiently small (large). Therefore, the sign is ambiguous. (iii) It follows immediately from (42).

The intuition for the results in Proposition 13 is as follows. More direct information provision only has a direct positive effect on the quality of the public provider. On the contrary, it has two side effects on the quality of the private provider as it depends on the size of $\lambda$. The role of $\lambda$ is through strategic interaction. If $\lambda$ is large, the public provider is the high-quality provider (cf. Proposition 1). The larger (smaller) $\lambda$ is, the stronger (weaker) is the strategic (negative) effect on $q_{2}$ due to $\frac{\partial q_{2}}{\partial q_{1}}<0$. In this case, the indirect negative effect outweighs the direct effect and the private provider reacts to an increase in $\beta$ by reducing quality if $\lambda$ is large (and vice versa in case of a small $\lambda)$.

In our model settings, the private provider favours the policy-induced step towards disclosing the table leagues and published reports, if the public provider received low state subsidy. However, in the presence of altruism, as we have shown in the numerical example, under certain circumstances, the public provider responds to increased public reporting by decreasing the quality, if it is not highly motivated. 
Under certain circumstances, we notice that more information does not always lead to higher quality and price for the private provider. Hence, it is essential to evaluate the effect of more information on the average quality in equilibrium. We differentiate the average quality in (16) with respect to $\beta$ (when both providers seek profit-orientation): ${ }^{26}$

$$
\frac{\partial \bar{q}}{\partial \beta}=\frac{\beta^{4} \lambda\left(11 k t-\beta^{2}\right)+k \beta^{2} \lambda^{2}\left(12 k t+\beta^{2}\right)+24 k^{2} t^{2} \lambda\left(2 k t-3 \beta^{2}\right)+\rho}{4 k t\left(4 k t-\beta^{2}\right)^{3}}
$$

where $\rho=(c-T)\left(4 k t-\beta^{2}\right)\left(k \lambda\left(4 k t+\beta^{2}\right)-k t\left(20 k t-7 \beta^{2}\right)-\beta^{4}\right)+4 k^{2} t^{3}\left(4 k t+3 \beta^{2}\right)$

Proposition 14: If the public provider seeks profit orientation, the average quality provision unambiguously increases in response to more available information.

Proof: If $\alpha=0$, the numerator in (43) is monotonically increasing in $\lambda$ if $\beta$ is sufficiently small $\left(\frac{\partial()}{\partial \lambda}=k(c-T)\left(4 k t-\beta^{2}\right)\left(4 k t+\beta^{2}\right)+\beta^{4}\left(11 k t-\beta^{2}\right)\right.$ $\left.+2 k \beta^{2} \lambda\left(12 k t+\beta^{2}\right)+24 k^{2} t^{2}\left(2 k t-3 \beta^{2}\right)\right)$. Otherwise, for sufficiently large $\beta$, the numerator in (43) reduces to: $-128 k^{3} t^{2}(t-\lambda) \lessgtr 0$. Setting $\lambda=\bar{\lambda}$ reduces the numerator $\mathrm{L}$ to:

$L=\frac{4 k t}{\beta^{2}}\left(4 k t-\beta^{2}\right)^{2}(T-c+t)\left(4 k t-\beta^{2}+2 k(t+T-c)\right)>0$

Thus, $\frac{\partial \bar{q}}{\partial \beta}>0$ if $\lambda$ is sufficiently high. Similarly, setting $\lambda=\underline{\lambda}$ reduces the numerator L to: $4 k^{2} t\left(3 \beta^{2}+4 k t\right)(T-c+t)^{2}>0$. Regardless if the numerator is monotonically decreasing/increasing, $\mathrm{L}$ is positive. Thus, $\frac{\partial \bar{q}}{\partial \beta}>0$ for all $\lambda \in(\underline{\lambda}, \bar{\lambda})$.

\footnotetext{
${ }^{26}$ In the presence of altruism, we find a positive effect on average quality in response to increased public reporting, check Appendix
} 
The intuition is straightforward: more direct information provision (higher $\beta$ ) leads to more average quality in equilibrium. Regardless of $q_{1} \lessgtr q_{2}$, increased available information has potentially small negative effect on the private provider's incentive quality provision if $\lambda$ is large. In sum, this leads to higher average quality in equilibrium.

\section{$6 \quad$ Policy Implications and Concluding Remarks}

This paper introduces the importance of state subsidies and co-payment fees in mixed markets, where public and private providers coexist. In a setting where the public provider faces a regulated market and is partly motivated towards quality, we investigate the effect of competition on quality provision. In addition, we explore the effects of changes in key policy instruments on equilibrium outcomes. To this end, our analysis has been conducted within a spatial competition framework as it is well-suited to study the relationship between competition and quality provision in sectors like healthcare, education, nursing homes and elderly care. We shed light on some of the mechanisms that lead to the widespread phenomenon of variations in quality differentiation in mixed markets.

Our theoretical analysis produces two main results. First, under certain circumstances, increased competition leads to lower average quality in equilibrium. This negative relationship also holds if the public provider is partly motivated compared to a benchmark case where both providers seek profitmaximisation. In our model, we find that increased competition has an ambiguous effect on quality for the public provider. Policy measures aimed at increasing competition between public and private provider may surprisingly reduce quality provision. The reasons stem from the size of the funds trans-

ferred to the public provider by the government and the purchasing power of consumers (i.e preferences towards higher quality). For example, it is widely 
common among emerging countries (Lebanon, Bangladesh and Egypt) for governments to allocate a small share of state subsidies to the public markets, which in turn, have weak incentives to provide higher quality due to its small profit margin.

The second key finding is that the effects of higher co-payment fees or larger state subsidies on average quality are also a priori ambiguous. More interestingly, we explore the effects of a higher share of co-payment on equilibrium outcomes (price and, more importantly, quality). The interests of policymakers in OECD in increasing co-payment fees as a possible solution for cost pressures, did not lead to the expected results (higher quality). Our analysis suggests that governments face trade off should they decide to increase one of these policy instruments. Recent empirical studies highlight the drawbacks of reducing spending and increasing co-payment fees on quality and consumer's demand, respectively (Landsem and Magnussen, 2018; Jakobsson and Svensson, 2016; Deming and Walters, 2017). However, these studies are carried out either on public institutions or under price regulation. Consequently, understanding the mechanisms of the payment system is crucial to achieve the desired allocation of public market resources. Our analysis can be evaluated empirically to examine how the provider's quality will respond to increased co-payment fees (or share of co-payment) and if the private provider can compete on quality, in addition to the price.

Our study additionally characterises the incentives to the private provider so as to relocate unilaterally towards the public provider. If the amount of state subsidy received by the public provider is sufficiently small, the private can maximise profits and steal market shares by relocating in the direction of the public provider. Furthermore, we demonstrated the features that lead to quality differentiation between the private and public providers in some countries. More specifically, if the market entails a high level of horizontal 
differentiation (diversity of services) relative to the state subsidy parameter, the private is the high-quality provider in the market.

The paper ignored some important features of the healthcare and education markets. Probably the most important limitation is that consumer preferences are not vertically differentiated. However, this feature would not render the current paper redundant as we highlighted the role of the consumers' marginal willingness-to-pay for quality (WTP). If there is a possibility for consumers to differ with respect to their WTP, how does this reflect on the strategic interaction between the competing providers' incentive for quality differentiation in the presence of various shocks (degree of competition, size (or share) of state subsidies and co-payment)? We will leave this for future research. In addition, an analysis of optimal regulation would require a fullyfledged welfare analysis, which lies beyond the scope of this paper. ${ }^{27}$

\section{Appendix}

\section{Equilibrium Existence for Quality}

$q_{1} \geq 0$ : The optimal quality for the public provider has to be always positive. As the numerator in equation (9) is monotonically increasing in the state subsidy $\lambda, q_{1} \geq 0$ if we have the following threshold value:

$$
\lambda \geq \underline{\lambda}:=c-T+\alpha \frac{\left[\bar{U}\left(\beta^{2}-4 k t\right)+4 t\left(\beta^{2}-3 k t+k(T-c)\right)\right]}{\left(4 k t-\beta^{2}\right)}
$$

As the amount of state funds reaches the lowest threshold $\left(\lim _{\lambda \longrightarrow \lambda}\right)$, then $q_{1}=0$ and the price for the private provider which is independent of altruism

\footnotetext{
${ }^{27}$ Our parametric framework is not well-suited for welfare analysis in the presence of fixed total demand. Indeed, in a profit-maximising duopoly, we concluded that both providers will set $p=c+t$, share half of the market share, and quality first-best is implemented.
} 
level is:

$$
p_{2}^{*}=\frac{c\left(2 k t-\beta^{2}\right)+2 k t(t+T)}{\left(4 k t-\beta^{2}\right)}
$$

$q_{2} \geq 0$ : The optimal quality for the private provider has to be strictly positive. As the numerator in equation (10) is always monotonically increasing in the state subsidy, $q_{2}^{*} \geq 0$ if we have the following threshold value:

$$
\lambda \leq \bar{\lambda}:=\frac{(T-c)\left(4 k t-\beta^{2}\right)+4 k t^{2}-\alpha \beta^{2}(5 t+T+\bar{U}-c)}{\beta^{2}}
$$

If we set $\lambda$ at its highest level $\bar{\lambda}$, then $q_{2}^{*}=0$ as $\lim _{\lambda \longrightarrow \bar{\lambda}}$ then $p_{2}^{*}=c$.

\section{Numerical Example}

The purpose of our numerical example is to tackle the outcomes theoretically unverified. Hence, we illustrate how quality provision and public reporting respond to more competition in the presence of public provider altruism. We consider consumers' marginal willingness-to-pay, $\beta$, is sufficiently high such that it is below the upper threshold, $\bar{\beta}:=4 k t$.

$(\alpha>0)$ : Table 1 highlights the case where $\beta$ is sufficiently high (close to $\bar{\beta}$ ) and $\lambda$ is sufficiently low (close to $\underline{\lambda}$ ). We aim to extend Propositions 5 and 11. We have two scenarios here. First, if the public provider is not a highly motivated agent $(\alpha=0.05$ or $\alpha=0.12$ ), increased competition induces the public provider to reduce quality provision $\left(\frac{\partial q_{1}^{*}}{\partial t}>0\right)$. This is explained in Proposition 2, the public provider has weak incentives to increase quality investments in the presence of low altruistic preferences. On the contrary, the private provider is induced to offer more quality and increase the price 
Table 1: Effects of Competition on $\bar{q}_{\alpha}$ and $\beta$ if $\alpha>0$

\begin{tabular}{|l|c|c|c|}
\hline$\alpha$ & 0.05 & 0.12 & 0.15 \\
\hline$q_{1}^{*}$ & 0.055 & 0.197 & 0.398 \\
\hline$q_{2}^{*}$ & 1.975 & 1.355 & 0.484 \\
\hline$W^{*}$ & 1.033 & 1.120 & 1.290 \\
\hline$\pi_{2}^{*}$ & 0.898 & 0.422 & 0.054 \\
\hline$p_{2}^{*}$ & 8.197 & 6.251 & 3.520 \\
\hline$D_{1}^{*}$ & 0.220 & 0.468 & 0.809 \\
\hline$\frac{\partial q_{1}^{*}}{\partial t}$ & $>\mathbf{0}$ & $>\mathbf{0}$ & $<0$ \\
\hline$\frac{\partial q_{2}^{*}}{\partial t}, \frac{\partial p_{2}^{*}}{\partial t}$ & $<0$ & $<0$ & $>\mathbf{0}$ \\
\hline$\frac{\partial q_{1}^{*}}{\partial \beta}$ & $<\mathbf{0}$ & $<\mathbf{0}$ & $>\mathbf{0}$ \\
\hline$\frac{\partial q_{2}^{*}}{\partial \beta}, \frac{\partial p_{2}^{*}}{\partial \beta}, \frac{\partial \bar{q}_{\alpha}}{\partial T}, \frac{\partial \bar{q}_{\alpha}}{\partial \beta}$ & $>0$ & $>0$ & $>0$ \\
\hline$\frac{\partial \bar{q}_{\alpha}}{\partial t}$ & $<\mathbf{0}$ & $<\mathbf{0}$ & $>\mathbf{0}$ \\
\hline$\frac{\partial \bar{q}_{\alpha}}{\partial \lambda}$ & $<0$ & $<0$ & $<0$ \\
\hline
\end{tabular}

The parameters satisfy the second order conditions, $B=1, \bar{U}=1, T=0.6$, $t=4, k=2, c=2, \beta=5.1, \underline{\lambda}<1.5<\bar{\lambda}, \bar{\beta}=4 k t=32$ and $\bar{\alpha}=0.193$

level accordingly. In this case, notice the negative marginal effect of marginal willingness-to-pay for quality, $\beta$, on the quality of the public provider. Conversely, if $\alpha=0.15$ (close to $\bar{\alpha}$ ), increased competition induces the public provider to increase the quality level. In this case, the relation between $\beta$ and $q_{1}^{*}$ is positive compared to the negative one at sufficiently low altruistic preferences. Consequently, if the public provider is highly motivated, $\frac{\partial q_{1}}{\partial t}<0$ if $\beta$ is high and $\lambda$ is low. Regardless of the level of $\alpha$, average quality is decreasing (increasing) in the state subsidy (co-payment). Vide Proposition 7 and 9 , respectively.

We conclude, out of this numerical example, that the impact of increased competition on the average quality depends on the mechanisms explained in the effect of competition on the quality of the private provider (direct versus indirect effect). Consequently, if $\alpha$ is sufficiently low (high), increased competition leads to higher (lower) average quality for sufficiently high $\beta$ and low 
$\lambda$, where the direct (indirect) effect dominates. Furthermore, considering $\beta$ as a direct information provision parameter, increased public reporting reduces the quality of the public if it is not highly motivated for sufficiently low $\lambda$. Nevertheless, average quality is increasing in response to more available information on the providers operating in the market. 


\section{References}

Amin, M. D., Badruddoza, S., and Rosenman, R. (2018). Quality Differentiation Under Mixed Competition in Hospital Markets. Journal of Industry, Competition and Trade, pages 1-12.

Bahr, P. R. (2014). The labor market return in earnings to community college credits and credentials in California.

Barron, D. N. and West, E. (2017). The quasi-market for adult residential care in the UK: Do for-profit, not-for-profit or public sector residential care and nursing homes provide better quality care? Social Science $\&$ Medicine, 179:137-146.

Barros, P. and Martinez-Giralt, X. (2002). Public and Private Provision of Health Care. Journal of Economics \& Management Strategy, 11:109-133.

Baum, S., Ma, J., Bell, D. W., and Elliott, D. C. (2014). Trends in College Pricing, 2014. Technical report, Trends in Higher Education Series. College Board.

Bemo, B. (2013). Hospitals in Lebanon. Technical report, Asset Management Unit, Beirut.

Bettinger, E. P. and Long, B. T. (2009). Addressing the needs of underprepared students in higher education does college remediation work? Journal of Human resources, 44(3):736-771.

Brekke, K. R., Nuscheler, R., and Rune Straume, O. (2006). Quality and location choices under price regulation. Journal of Economics $\&$ Management Strategy, 15(1):207-227.

Brekke, K. R., Nuscheler, R., and Straume, O. R. (2007). Gatekeeping in health care. Journal of Health Economics, 26(1):149-170. 
Brekke, K. R., Siciliani, L., and Straume, O. (2010). Price and quality in spatial competition. Regional Science and Urban Economics, 40(6):471480.

Brekke, K. R., Siciliani, L., and Straume, O. (2011). Hospital Competition and Quality with Regulated Price. The Scandinavian Journal of Economics, 113(2):444-469.

Brekke, K. R., Siciliani, L., and Straume, O. R. (2017). Can competition reduce quality? Journal of Institutional and Theoretical Economics.

Burgess, S., Propper, C., and Gossage, D. (2008). Competition and quality: evidence from the NHS internal market 1991-9. Economic Journal, 118:138-170.

Calem, P. and Rizzo, J. (1995). Competition and Specialization in the Hospital Industry: An Application of Hotelling's Location Model. Southern Economic Journal, 61:1182-1198.

Cellini, R., Siciliani, L., and Straume, O. R. (2018). A dynamic model of quality competition with endogenous prices. Journal of Economic Dynamics and Control, 94:190-206.

Chiappori, P. A., Durand, F., and Geoffard, P. Y. (1998). Moral hazard and the demand for physician services: First lessons from a French natural experiment. European Economic Review, 42(3-5):499-511.

Cockx, B. and Brasseur, C. (2003). The demand for physician services: Evidence from a natural experiment. Journal of Health Economics, 22(6):881913.

Cooper, Z., Gibbons, S., and Jones, S. (2011). Does hospital competition save lives? Evidence from the English NHS patient choice reforms. The Economic Journal, 121(554):F228-F260. 
Cremer, H. and Maldonado, D. (2013). Mixed oligopoly in education.

D'Aspremont, C., Gabszewicz, J. J., and Thisse, J. F. (1979). On Hotelling's "Stability in competition". Econometrica, 47:1145-1150.

De Fraja, G. and Iossa, E. (2002). Competition among universities and the emergence of the Elite Institution. Bulletin of Economic Research, 54(3):275-294.

Dee, T. S. (1998). Competition and the quality of public schools. Economics of Education Review, 17(4):419-427.

Deming, D. and Goldin, C. (2012). Does federal student aid raise tuition? New evidence on for-profit colleges.

Deming, D., Goldin, C., and Katz, L. (2012). The for-profit postsecondary school sector: nimble critters or agile predators? Journal of Economic Perspectives, 26(1):139-164.

Deming, D. J. and Walters, C. R. (2017). The impact of price caps and spending cuts on US postsecondary attainment. National Bureau of Economic Research, No. w23736.

Economides, N. (1989). Quality variations and maximal variety differentiation. Regional Science and Urban Economics, 19(1):21-29.

Epple, D. and Romano, R. (1998). Competition between private and public schools, vouchers, and peer-group effects. American Economic Review, 88:33-62.

Forder, J. and Allan, S. (2014). The impact of competition on quality and prices in the English care homes market. Journal of Health Economics, 34:73-83.

Francois, P. and Vlassopoulos, M. (2008). Pro-social motivation and the delivery of social services. CESifo Economic Studies, 54(1):2008. 
Friedman, L., Avila, S., Friedman, D., and Meltzer, W. (2019). Association between Type of Residence and Clinical Signs of Neglect in Older Adults. Gerontology, 65(1):30-39.

Gaynor, M., Moreno-Serra, R., and Propper, C. (2013). Death by market power: reform, competition, and patient outcomes in the National Health Service. American Economic Journal: Economic Policy, 5(4):134-166.

Gaynor, M. and Town, R. J. (2011). Competition in Health Care Markets.

Grabowski, D. (2004). A longitudinal study of Medicaid payment, privatepay price and nursing home quality. International Journal Health Care Finance and Economics, 4:5-26.

Gravelle, H. (1999). Capitation contracts: access and quality. Journal of Health Economics, 18(3):315-340.

Herr, A. (2011). Quality and Welfare in a Mixed Duopoly with Regulated Prices: The Case of a Public and a Private Hospital. German Economic Review, 12:422-437.

Hirth, R. A. (1997). Competition between for-profit and nonprofit health care providers: Can it help achieve social goals? Medical Care Research and Review, 54(4):414-438.

Hotelling, H. (1929). Stability in Competition. Economic Journal, 39:41-57.

Hoxby, C. (1994). Do private schools provide competition for public schools?

Jakobsson, N. and Svensson, M. (2016). Copayments and physicians visits: A panel data study of swedish regions 2003-2012. Health Policy, 120(9):10951099.

Jeurissen, P., Duran, A., and Saltman, R. (2016). Uncomfortable realities: the challenge of creating real change in Europe's consolidating hospital sector. BMC Health Services Research, 16(2):16-23. 
Kessler, D. and McClellan, M. (2000). Is hospital competition socially wasteful? Quarterly Journal of Economics, 115:577-615.

Klumpp, T. and Su, X. (2018). Price-Quality Competition in a Mixed Duopoly.

Laine, L. T. and Ma, C. T. A. (2017). Quality and competition between public and private firms. Journal of Economic Behavior $\mathscr{G}$ Organization, 140:336-353.

Landsem, M. M. and Magnussen, J. (2018). The effect of copayments on the utilization of the GP service in Norway. Social Science 8 Medicine, 205:99-106.

Ma, C. T. A. and Burgess, J. F. (1993). Quality competition, welfare, and regulation. Journal of Economics, 58(3):153-173.

Makris, M. (2009). Incentives for motivated agents under an administrative constraint. Journal of Economic Behavior and Organization, 71(2):428440 .

Matsumura, T. and Matsushima, N. (2007). Congestion-reducing investments and economic welfare in a Hotelling model. Economics Letters, 96(2):161-167.

OECD (2017). Choice, Competition and Markets: Education, Healthcare, and Public Services. Technical report, OECD.

Pavel, M. S., Chakrabarty, S., and Gow, J. (2015). Assessing willingness to pay for health care quality improvements. BMC health services research, 15(1):43.

Prendergast, C. (2007). The motivation and bias of bureaucrats. The American Economic Review, pages 180-196. 
Propper, C., Burgess, S., and Green, K. (2004). Does competition between hospitals improve the quality of care? Hospital death rates and the NHS internal market. Journal of Public Economics, 88:1247-1272.

Romero, L. and Del Rey, E. (2004). Competition between public and private universities: quality, prices and exams.

Sabik, L. and Gandhi, S. O. (2016). Copayments and emergency department use among adult Medicaid enrollees. Health economics, 25(5):529-542.

Stenbacka, R. and Tombak, M. (2015). Competition between For-Profit and Nonprofit Healthcare Suppliers and Quality.

Stenbacka, R. and Tombak, M. (2018). Optimal Reimbursement Policy in Health Care: Competition, Ownership Structure and Quality Provision. The BE Journal of Economic Analysis \& Policy, 18(1).

Tay, A. (2003). Assessing competition in hospital care markets: the importance of accounting for quality differentiation. The RAND Journal of Economics, 34:786-814.

Tonin, M. and Vlassopoulos, M. (2010). Disentangling the sources of prosocially motivated effort: A field experiment. Journal of Public Economics, 94(11):1086-1092.

Wolinsky, A. (1997). Regulation of duopoly: managed competition vs regulated monopolies. Journal of Economics 83 Management Strategy, $6(4): 821-847$. 


\section{Most Recent Working Paper}

NIPE WP

02/2019

NIPE WP

01/2019

NIPE WP

21/2018

NIPE WP

20/2018

NIPE WP

19/2018

NIPE WP

18/2018

NIPE WP

17/2018

NIPE WP

16/2018

NIPE WP

15/2018

NIPE WP

14/2018

NIPE WP

13/2018

NIPE WP

12/2018

NIPE WP

11/2018

NIPE WP

10/2018

NIPE WP

09/2018

NIPE WP

08/2018

NIPE WP

07/2018

NIPE WP

06/2018

NIPE WP

05/2018

NIPE WP

04/2018

NIPE WP

03/2018

NIPE WP

02/2018

NIPE WP

01/2018

NIPE WP

13/2017

NIPE WP

12/2017

NIPE WP

11/2017

NIPE WP

10/2017

Ghandour, Ziad R., "Public-Private Competition in Regulated Markets", 2019

Alexandre, Fernando, Pedro Bação e Miguel Portela, "A flatter life-cycle consumption profile", 2019

Veiga, Linda, Georgios Efthyvoulou e Atsuyoshi Morozumi, "Political Budget Cycles: Conditioning Factors and New Evidence", 2018

Sá, Luís, Luigi Siciliani e Odd Rune Straume, "Dynamic Hospital Competition Under Rationing by Waiting Times", 2018

Brekke, Kurt R., Chiara Canta, Luigi Siciliani e Odd Rune Straume, "Hospital Competition in the National Health Service: Evidence from a Patient Choice Reform", 2018

Paulo Soares Esteves, Miguel Portela e António Rua, "Does domestic demand matter for firms' exports?", 2018

Alexandre, Fernando, Hélder Costa, Miguel Portela e Miguel Rodrigues, "Asymmetric regional dynamics: from bust to recovery", 2018

Sochirca, Elena e Pedro Cunha Neves, "Optimal policies, middle class development and human capital accumulation under elite rivalry", 2018

Vítor Castro e Rodrigo Martins, "Economic and political drivers of the duration of credit booms", 2018

Arash Rezazadeh e Ana Carvalho, "Towards a survival capabilities framework: Lessons from the Portuguese Textile and Clothing industry", 2018

Areal, Nelson e Ana Carvalho, "Shoot-at-will: the effect of mass-shootings on US small gun manufacturers", 2018

Rezazadeh, Arash e Ana Carvalho, "A value-based approach to business model innovation:

Defining the elements of the concept", 2018

Carvalho, Ana e Joaquim Silva, "The Work Preferences of Portuguese Millennials - a Survey of University Students", 2018

Souza, Maria de Fátima e Ana Carvalho, "An Organizational Capacity model for wine cooperatives", 2018

Kurt R. Brekke, Tor Helge Holmås, Karin Monstad e Odd Rune Straume, "How does the type of remuneration affect physician behaviour? Fixed salary versus fee-for-service", 2018

Martins, Susana e Cristina Amado, "Financial Market Contagion and the Sovereign Debt

Crisis: A Smooth Transition Approach", 2018

Amado, Cristina, Annastiina Silvennoinen e Timo Teräsvirta, "Models with Multiplicative

Decomposition of Conditional Variances and Correlations", 2018

Lisi, Domenico, Luigi Siciliani e Odd Rune Straume, "Hospital Competition under Pay-for-

Performance: Quality, Mortality and Readmissions", 2018

Magalhães, Pedro C. e Luís Aguiar-Conraria, "Procedural Fairness, the Economy, and Support for Political Authorities", 2018

Aguiar-Conraria, Luís, Manuel M. F. Martins e Maria Joana Soares, "Estimating the Taylor

Rule in the Time-Frequency Domain", 2018

Sousa, Rita, Elsa Agante, João Cerejeira e Miguel Portela, "EEE fees and the WEEE system -

A model of efficiency and income in European countries", 2018

Sochirca, Elena e Francisco José Veiga, "Key determinants of elite rivalry: theoretical insights and empirical evidence", 2018

Siciliani, Luigi e Odd Rune Straume, "Competition and Equity in Health Care Market", 2018

Aguiar-Conraria, Luís, Maria Joana Soares e Rita Sousa, "California's Carbon Market and Energy Prices: A Wavelet Analysis", 2017

Mustapha Olalekan Ojo, Luís Aguiar-Conraria e Maria Joana Soares, "A time-frequency analysis of the Canadian macroeconomy and the yield curve", 2017.

Sousa, Rita, Adérito Santana e Inês Mourão, "Low-Emission Energy Outlook in a Small Island

Developing States - The case of Sao Tome And Principe", 2017

Vareiro, Laurentina, J. Cadima Ribeiro e Paula Remoaldo, "Destination attributes and tourist's

satisfaction in a cultural destination", 2017 